\title{
Crashworthiness study on hybrid energy absorbers as vertical struts in civil aircraft fuselage designs
}

\author{
J. Paz ${ }^{1}$, J. Díaz ${ }^{2}$, L. Romera ${ }^{3}$, \\ Universidade da Coruña - Structural Mechanics Group, School of Civil Engineering \\ 15071 A Coruña, Spain \\ F. Teixeira-Dias ${ }^{4}$, \\ The University of Edinburgh - School of Engineering, Edinburgh EH9 3JL, UK
}

\begin{abstract}
This research concerns the crashworthiness study and enhancement of commercial aircraft fuselage structures by incorporating crushable hybrid energy absorbers to work as vertical struts. To assess their contribution on a representative aircraft structure, a numerical simulation of a Boeing 737-200 drop test is developed and validated with experimental data available in the literature. The fuselage section is then simulated both with and without the fuel tank, showing more harmful effects for the latter scenario. The numerical model accurately captures the experiment's collapse process with low artificial energy ratios. Later, four vertical hybrid energy absorbers designed for programmed and progressive collapse, are added in the cargo compartment, connecting the underfloor beams and the frames. Different designs and positions are studied, combining aluminum tubes with square and circular cross-sections, filled with a core made from a GFRP skeleton and foam extrusions. Acceleration graphs show a reduction in passenger injury levels from severe to moderate according to an Eiband diagram when energy absorbers are fitted. Energy trends from the hybrid absorbers are also monitored, with dissipation of up to $10 \mathrm{~kJ}$ of the fuselage's kinetic energy through plastic deformation and collapse. Results also show a significant improvement on the global crashworthiness of the fuselage, leading to an increase in plastic dissipation by the frames from $76 \mathrm{~kJ}$ to $122 \mathrm{~kJ}$ and a reduction on the accelerations up to $50 \%$ when the energy absorbing structures are added.

Keywords: Crashworthiness enhancement, numerical model validation, Eiband diagram, hybrid energy absorbers
\end{abstract}

\footnotetext{
${ }^{1}$ PostDoc reasearcher. Corresponding author. (javier.paz.mendez@udc.es).Tel: +34 881016017 ; Fax: +34981167170

${ }^{2}$ Associate Professor

${ }^{3}$ Associate Professor

${ }^{4}$ Senior Lecturer
} 


\section{Introduction}

Since the early days of flight, and particularly after the 1960s, efficiency and safety have become one of the most important issues in the aviation industry. To address this, materials with high strength-to-weight ratios, such as metallic alloys and composite materials, have been tested and introduced in aircraft, significantly reducing the weight of the different components and structures. Crashworthiness tests and standards, such as those established by the Federal Aviation Administration (FAA) or by the Joint Airworthiness Requirements (JAR) [1], have noticeably increased the survival probabilities and reduced passenger injuries in crash scenarios. A crashworthiness improvement of an aircraft combines the improvement of both its structure and the materials, so that it exhibits exceptional crash resistance and energy-absorption capabilities for passenger protection. Different techniques are used to improve the crashworthiness of an aircraft, such as modifying its response to failure or increasing the energy that can be absorbed by the structure. However, experimental tests and simulations are required to assess the actual improvements of the aircraft's response under impact and to obtain conclusive data on the structural response and the loads and accelerations transmitted to the passengers.

Research laboratories such as the Impact Dynamics Research Facility at NASA Langley Research Center in Virginia (USA), and the William J. Hughes Technical Center in New Jersey (USA), have performed a number of full-scale aircraft and rotorcraft crash tests since the 1970s [2]. Among the more than one hundred tests performed, some have been made with front, centre and aft fuselage sections of the Boeings 707, 720 and 737. The data obtained has been used since then as validation for finite-element crashworthiness simulations, thus reducing the number of experimental tests required to assess the performance under different impact conditions [3-5]. The crash simulations gradually evolved from simple models based on beams and lumped masses to the more complex models used nowadays.

Many research teams have focused on the improvement of different areas of aircraft structures instead of the more intricate fuselage section, including subfloor structures, the fuselage stiffeners or the vertical struts connecting the frame with the under-floor beams [6]. By adding sub-floor enhancements, more energy is dissipated during a hard-landing or a water-ditching scenario, thus reducing the energy dissipated by other components of the structure [7], which can translate into less severe passenger injuries.

The vertical struts provide support for the floor structures and, in the event of an im- 
pact, they are mainly subjected to axial loads. The crashworthiness of an aircraft depends on the behavior of these structures: rigid struts help dissipate more energy on the lower sections of the aircraft, while flexible struts would maintain the integrity of the cabin's survivable cell after a crash $[8,9]$. Research on the vertical struts has recently gained significance, with investigations looking into the effect of the configuration, location and orientation [10], the analysis of their crush behavior [11, 12], and the effect of the use of triggers [13].

The implementation and improvement of vertical struts in aircraft fuselages can lead to a reduction in weight and costs while simultaneously improving the crashworthiness of the aircraft [14]. This can be done by modifying the kinematic crash response of the aircraft and, therefore, reducing thickness of other heavier and more expensive components.

This investigation is focused on the development and improvement of novel energy absorption devices for aeronautical applications. Considering that one of the aims is that of identifying the effects of crushable struts on the structural collapse mechanism of the aircraft, the usage of a simplified fuselage section was deemed inadequate. Consequently, the first goal was developing a numerical aircraft model with a realistic dynamic behavior under impact scenarios to be used as a baseline. This was fulfilled with the simulation of a Boeing 737-200 fuselage section and its validation under both static internal pressure tests and hard-landing scenarios. Once the model is verified, a comparison between the crushing evolution and crashworthiness metrics originated from the experimental test and the finite element model is presented. Later, four vertical struts made from thin-walled aluminum tubes reinforced with a GFRP and foam core are added to the fuselage. The numerical model is tested again for comparison and crashworthiness analysis in two impact scenarios, either featuring or lacking the auxiliary fuel tank. The improvement induced by these structures is assessed according to aircraft efficiency and crashworthiness criteria.

\section{Fuselage model description}

The experimental drop test on which this investigation is based was performed in November of 2000 at the FAA William J. Hughes Technical Center (New Jersey, USA) [15]. In this test, a $3.048 \mathrm{~m}$ long section of a Boeing 737-200 was dropped from a height of $4.27 \mathrm{~m}$ as shown in figure 1. The initial impact against solid ground occurred at $9.144 \mathrm{~m} / \mathrm{s}$, thus constituting a severe but survivable crash.

In this previous experiment, the fuselage was thoroughly instrumented to record both accelerations and strains at a significant number of locations. The obtained data is used 


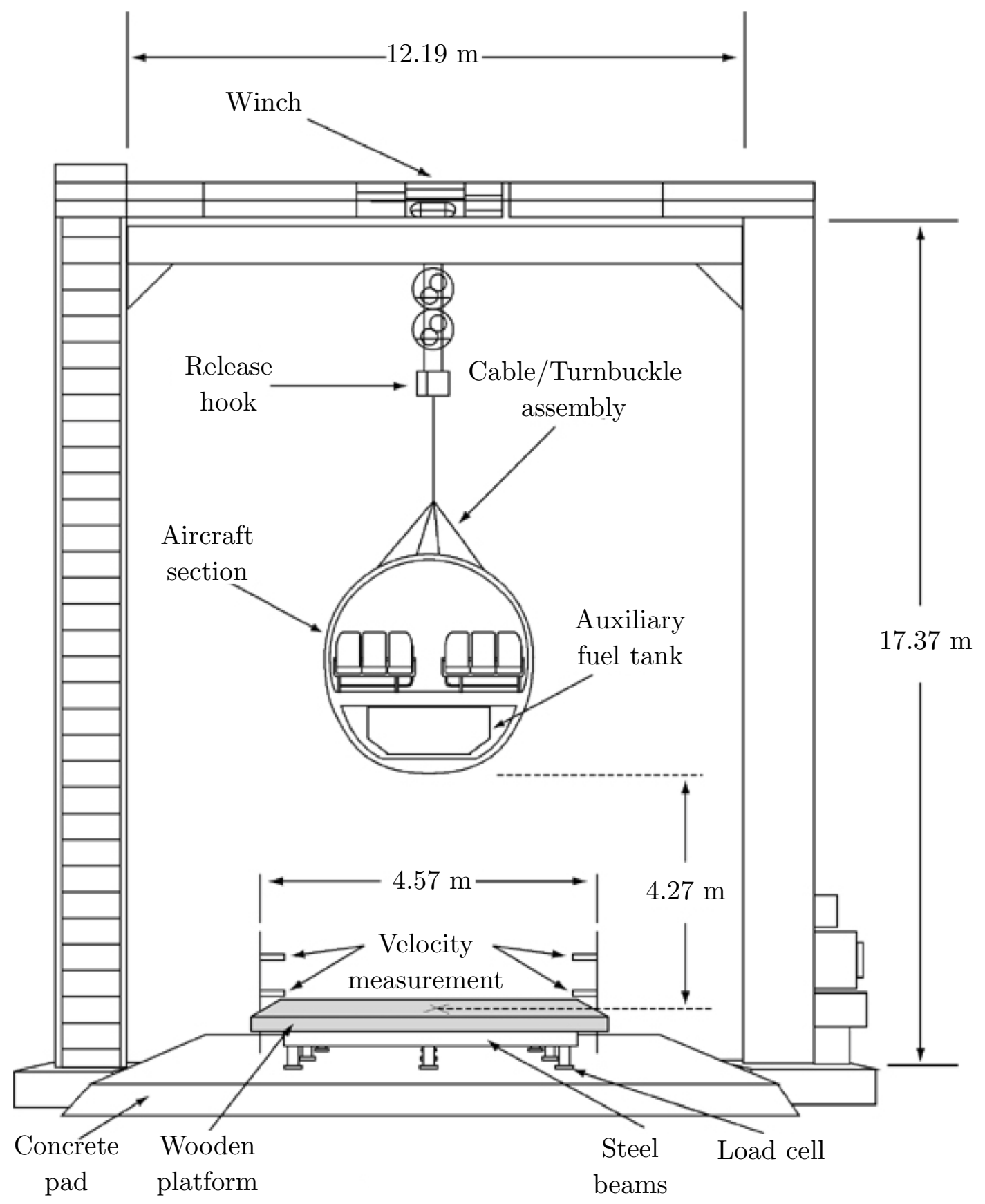

Figure 1: Dynamic drop test facility diagram. Adapted from Abromowitz et al. [16]. 
to check the validity of the proposed numerical model. The acceleration-history plots were also studied in an Eiband diagram [17] at four different locations, thus assessing the effects suffered by the passengers during the impact.

As previously mentioned, a finite element numerical model of a Boeing 737-200 fuselage section was developed and validated. Hereunder, the materials, numerical simulation parameters and analysis settings used for the simulation of the 10-foot vertical drop test are described in detail.

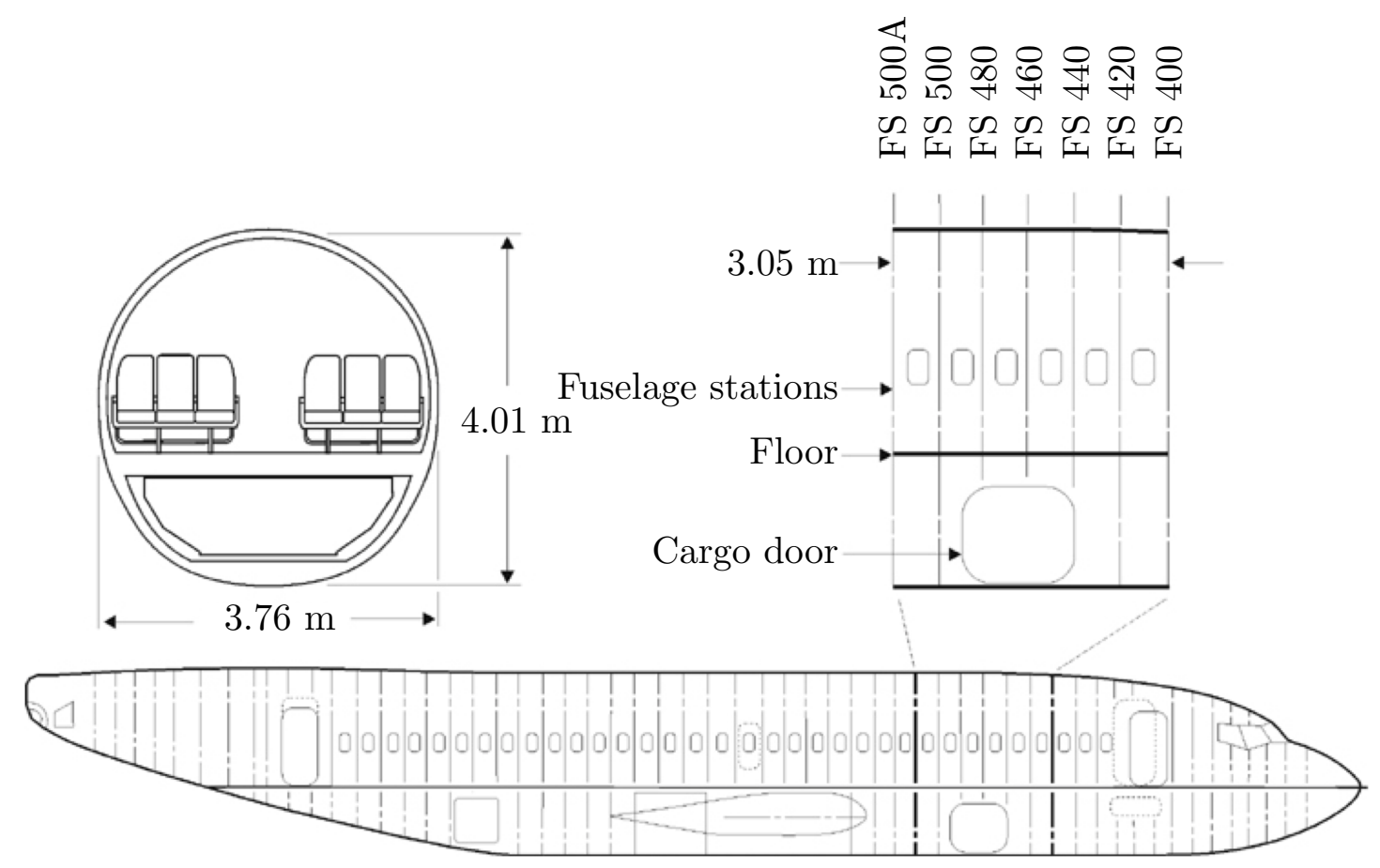

Figure 2: Boeing 737-200 test section. Adapted from [16].

The specimen tested is the fuselage section between stations FS400 and FS500A, as shown in figure 2. The model's main structures are the outer fuselage skin, seven evenlyspaced frames, the passenger floor and its seven supporting beams. In order to compensate for the loss of structural stiffness caused by removing the rest of the fuselage, two underfloor beams are added, one on each end of the section (stations FS400 and FS500A), as shown in figure 3 . The specimen also includes the mass of six triple-occupant seats with 18 passengers as point masses along the inner and outer seat tracks. A mass of approximately $1700 \mathrm{~kg}$ accounts for the auxiliary full fuel tank in the under-floor compartment. The cargo door and its reinforced door frame are also part of this section, stiffening the lower right part of the fuselage, thus modifying the collapse mechanisms (e.g. making them non-symmetrical) and the monitored metrics during the actual test [5].

Once the numerical model with the fuel tank is validated with the experimental re- 


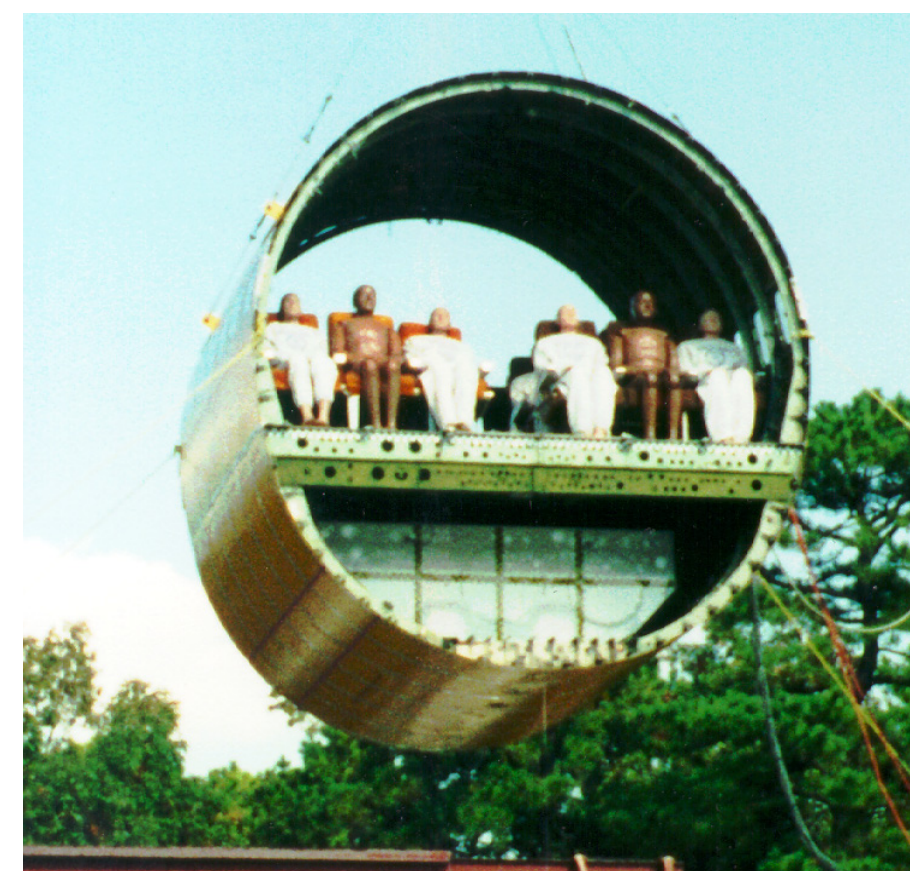

Figure 3: Boeing 737-200 test article. Taken from [15].

sults from Fasanella and Jackson [15], it is used as a benchmark and compared against a fuselage section with the vertical struts implemented. Seeking the crashworthiness improvement of the craft, honeycomb-filled energy absorbers as those developed in [12] were initially added to the model. However, after several preliminary tests, they proved too rigid for the impact conditions of this study, developing only one fold at the most and barely deforming in the post-buckling region as seen in figures $4 \mathrm{a}$ and $4 \mathrm{~b}$. Moreover, little energy was dissipated, resulting in low sub-floor deformation on account of excessive acceleration peak loads and significantly drawing the Eiband graph onto the severe-injury region. Following the same concept, two versions of the hybrid absorbers offering lower stiffness and complexity were considered, also combing GFRP and foam structures as a reinforcement. Two designs for the metallic tube are considered, namely with square and circular cross-sections as shown in figures $5 \mathrm{a}$ and $5 \mathrm{~b}$. The design of the outer tubes is constrained by the condition of similar mass and a material thickness of $1.5 \mathrm{~mm}$, yielding cross-sections with an edge of $55 \mathrm{~cm}$ for the square tube and a diameter of $70 \mathrm{~cm}$ for the circular variant.

The assembly of the HEA displayed in figure 6 also shows the beams connecting the absorber with the frames and floor beams. These bars are stiffer than the HEA, thus localizing the deformation under compression in the region of the absorber, and are connected to the frames and floor beams with pinned joints which can rotate only in the transverse plane.. Moreover, two plates are used on the upper and lower edges of the tube as to 


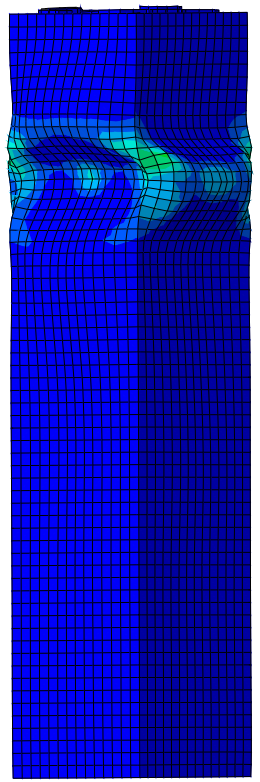

(a) Outer tube deformation.

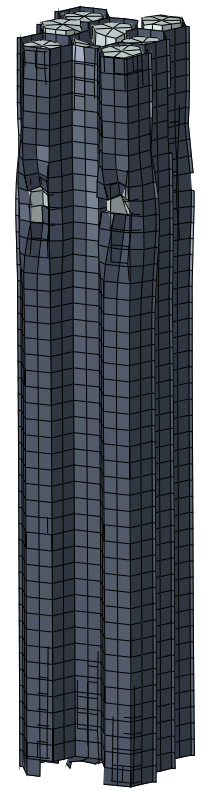

(b) Inner reinforcement.

Figure 4: Post-test deformation of honeycomb- and foam-filled hybrid energy absorber featured as vertical strut.

homogeneously distribute the axial compressive loads along the borders. The squaresectioned struts are rotated $45^{\circ}$ around the vertical axis so that their inertia is highest in the transverse plane to avoid off-plane global buckling.

A clearance of $2.04 \mathrm{~m}$ between struts is ensured so that the necessary capacity for the cargo containers and auxiliary fuel tanks is not compromised [18], although a scenario with the HEAs $2.20 \mathrm{~m}$ apart is also considered. The struts span every two meters along the longitudinal plane if attachment is feasible. In the section studied, only four struts were fitted, as visible in figure 8.

\subsection{Materials}

The Boeing 737-200 test article studied is made from three different materials. The fuselage skin and floor are made from AA2024-T3 aluminum, whereas the AA7075-T6 aluminum alloy was used for the frames, under-floor beams, stringers and the connector for the energy absorbers. The outer tube for the crushable vertical struts fitted for the second part of the research were also made from AA2024-T3 as it offers failure strain values of $18 \%$ required for progressive fold formation. Both materials have been modeled according to the Johnson-Cook strain-rate sensitive plasticity models [19] without temperature effects. The plasticity constitutive equation for both materials is

$$
\sigma_{y}=\left[A+B\left(\varepsilon_{p}^{e f f}\right)^{n}\right]\left(1+C \ln \dot{\varepsilon}^{*}\right)
$$




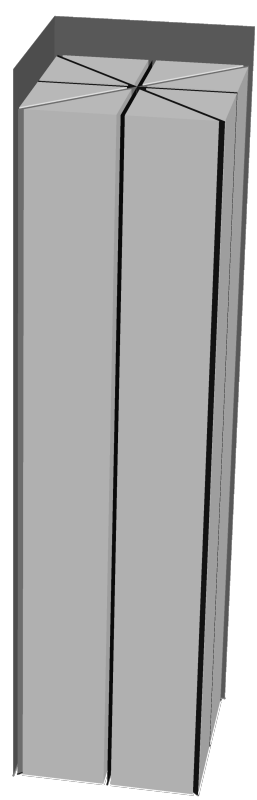

(a) Square cross-section.

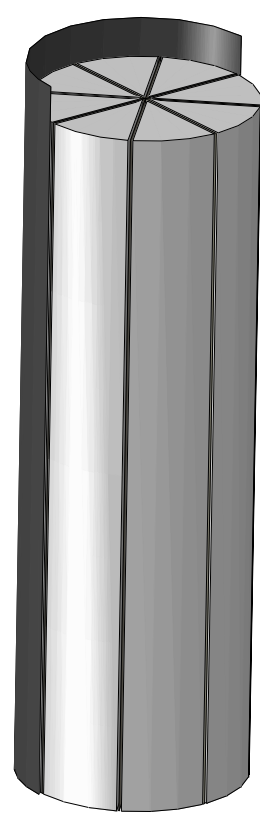

(b) Circular cross-section.

Figure 5: Three-dimensional cut of the hybrid energy absorber.

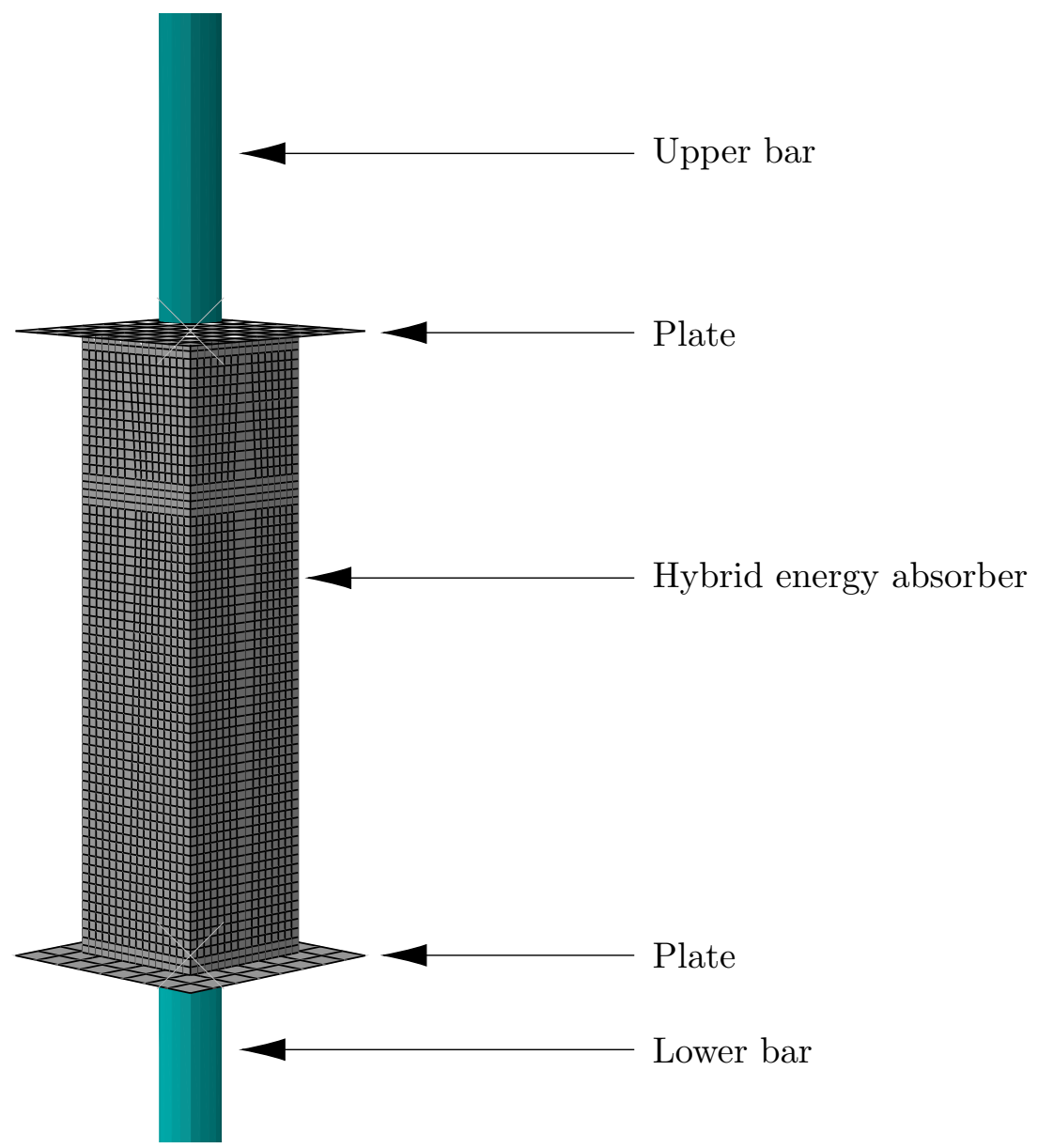

Figure 6: Detailed view of the hybrid energy absorber, connecting bars and surrounding structures. 
where $A$ is the material's yield stress, $B$ is the hardening law's amplitude modifier, $\varepsilon_{p}^{e f f}$ is the equivalent plastic strain, $\dot{\varepsilon}^{*}=\dot{\varepsilon} / \dot{\varepsilon}_{0}$ is the dimensionless equivalent plastic strainrate, and $C$ is the strain-rate's dependency modifier. The material properties were initially taken from Kay [20] for the AA2024-T3 aluminum and from Brar et al. [21] for the AA7075-T6 alloy. However, the test article was obtained from an used aircraft [15], consequently accounted for by reducing the values for the elastic and plastic parameters due to damage and fatigue by $20 \%$ as recommended by Fasanella and Jackson [22] and empirically adjusting the values of $C$ and $\dot{\varepsilon} / \dot{\varepsilon}_{0}$. The values used for the Johnson-Cook plasticity models implemented are detailed in table 1 . The fuel tank is a significant feature, therefore capable of noteworthy effects on the collapse mechanism of the fuselage. The properties for the tank material were taken from Fasanella and Jackson [15] and also detailed in table 1 . The impacting surface used in the test was made from wood, with material properties listed in table 1.

\begin{tabular}{llrrrr}
\hline \multicolumn{2}{c}{ Parameter } & AA2024-T3 & AA7075-T6 & Tank & Wood \\
\hline \multirow{2}{*}{ General } & $\mathrm{E}(\mathrm{GPa})$ & 73.08 & 72.40 & 72.40 & 0.50 \\
properties & $v$ & 0.33 & 0.33 & 0.30 & 0.30 \\
& $\rho\left(\mathrm{kN} / \mathrm{m}^{3}\right)$ & 2.78 & 2.78 & 4.94 & 1.20 \\
\hline \multirow{5}{*}{ Plasticity } & $\mathrm{A}(\mathrm{MPa})$ & 302 & 413 & 683 & - \\
model & $\mathrm{B}(\mathrm{MPa})$ & 550 & 600 & - & - \\
& $\mathrm{n}$ & 0.73 & 0.71 & - & - \\
& $\mathrm{C}$ & $3 \cdot 10^{-4}$ & $1 \cdot 10^{-4}$ & - & - \\
& $\dot{\varepsilon_{0}}$ & $5 \cdot 10^{-4}$ & $5 \cdot 10^{-4}$ & - & - \\
\hline
\end{tabular}

Table 1: Material properties of the AA2024-T3 [20], AA7075-T6 [21] aluminum alloys, the tank material [15] and the impacting block.

Concerning the materials for the inner core of the hybrid energy absorbers, the glassfiber-reinforced polyamide Ultramid A3WG10 BK00564 from BASF is used for the inner plates and a polymeric foam from Armacell (ArmaFORM PET/W AC 135) fills the void cells. The material constitutive model for the GFRP has been calibrated after the data recorded from the tensile tests by Costas et al. [23], and follows the form

$$
\sigma_{y}=\sigma_{0}+\left[\sum_{j=1}^{k} Q_{j}\left(1-e^{-b_{j} p}\right)\right],
$$

where $Q_{j}, b_{j}$ and $\sigma_{0}$ are material constants, and $k$ is the number of terms used to approximate the material's response. For this material, $k=2$, with a true strain at failure of 2.38\%. The density and the Poisson's modulus have been extracted from the manufac- 
turer's data sheets [24]. All data is listed in table 2.

\begin{tabular}{cccccccc}
\hline $\mathrm{E}(\mathrm{GPa})$ & $v$ & $\rho\left(\mathrm{kN} / \mathrm{m}^{3}\right)$ & $\sigma_{0}(\mathrm{MPa})$ & $Q_{1}(\mathrm{MPa})$ & $Q_{2}(\mathrm{MPa})$ & $b_{1}$ & $b_{2}$ \\
\hline 15.48 & 0.4 & 15.15 & 25.00 & 124.86 & 44.46 & 315.89 & 5748.46 \\
\hline
\end{tabular}

Table 2: Material properties of Ultramid A3WG10 BK00564.

As for the foam, various material tests were performed by Costas et al. [23] in order to obtain its behavior under compressive loads. Despite being an orthotropic material, it was considered that the foam was loaded parallel to the extrusion (or strong) direction. The mechanical properties used to model this material have been detailed in table 3 . An isotropic foam hardening model proposed by Deshpande and Fleck [25] for metallic foams was used to model the foam's behavior, which includes a pressure-dependent yield surface $f$ influenced by the shape factor $\alpha$, and a flow potential $g$ used to represent nonassociated flow that depends on the shape factor $\beta$ and the plastic Poisson's ratio $\nu_{\mathrm{p}}$. The values for the material model parameters are itemized in table 3.

\begin{tabular}{cccccc}
\hline$E$ & $v$ & $\rho$ & $\alpha$ & $\beta$ & $v_{\mathrm{p}}$ \\
\hline $59.01 \mathrm{MPa}$ & 0.10 & $1.35 \mathrm{kN} / \mathrm{m}^{3}$ & 0.729 & 1.76 & 0.111 \\
\hline
\end{tabular}

Table 3: Material properties of ArmaFORM PET/W AC 135.

\subsection{Numerical simulation}

The fuselage section was developed using the Abaqus CAE package (ver. 2016) [26] and represented all the significant structural features of the test specimen, including the skin stiffeners, the cargo door and its stiffening beams, the mass of seats and passengers and the filled auxiliary fuel tank. A total of 12 accelerometers recorded data from the experimental test article. The location of two, shown in figure 7 as locations $\mathbf{1}$ and $\mathbf{2}$, were chosen as acceleration monitoring points for the validation of the numerical simulation. Location 1 is the data extraction point on the left side of the station FS420 and $\mathbf{2}$ the point on the right; both measured at the fuselage floor. The data points $\mathbf{1 b}$ and $\mathbf{2 b}$ are also at the floor and vertically aligned with the location of the energy absorbers at FS420, and its metrics are also monitored to ensure that the use of the hybrid energy absorbers does not lead to excessive acceleration values at those points.

Four-node shell elements with reduced integration (S4R) and five integration points through the thickness solved through Simpson were used to model the skin and floor, 


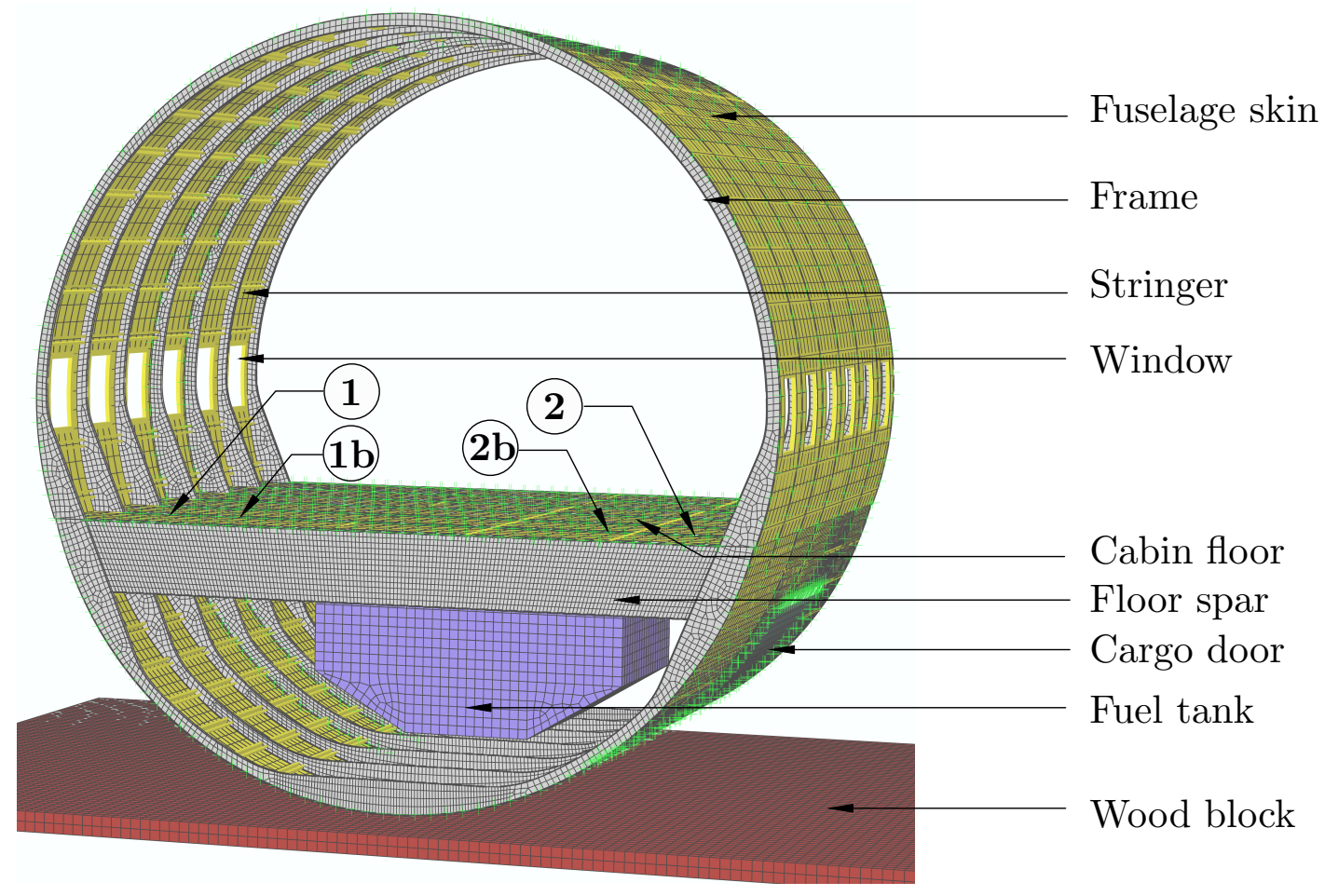

Figure 7: Numerical model in Abaqus 2016.

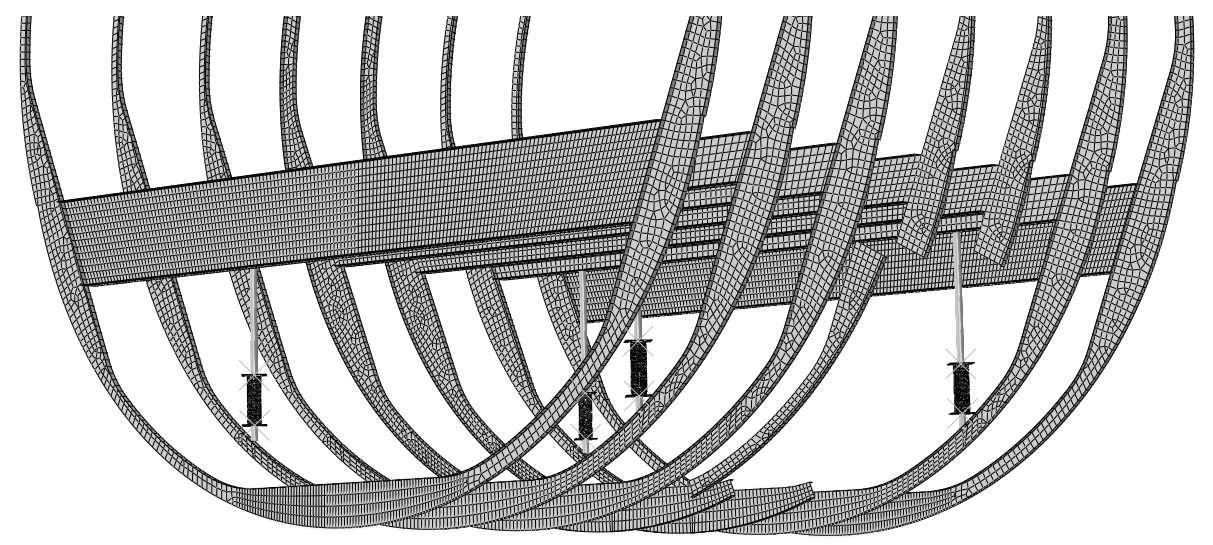

Figure 8: Detail of main frames the hybrid energy absorbers. 
frames, under-floor beams and tank panels. The usage of shell elements represents more accurately the actual behavior of the specimen and allows for an accurate representation of plastic hinges, whereas beam elements would not reproduce local buckling and crippling. However, the omega-shaped longitudinal stringers shown in figure 9 are modeled as 2node linear beam elements (B31) in order to reduce the number of elements in the model and the computational cost. The passenger-seat blocks are approximated with evenly distributed lumped masses. Solid eight-node elements with reduced integration (C3D8R) were used for the impacting surface's mesh.

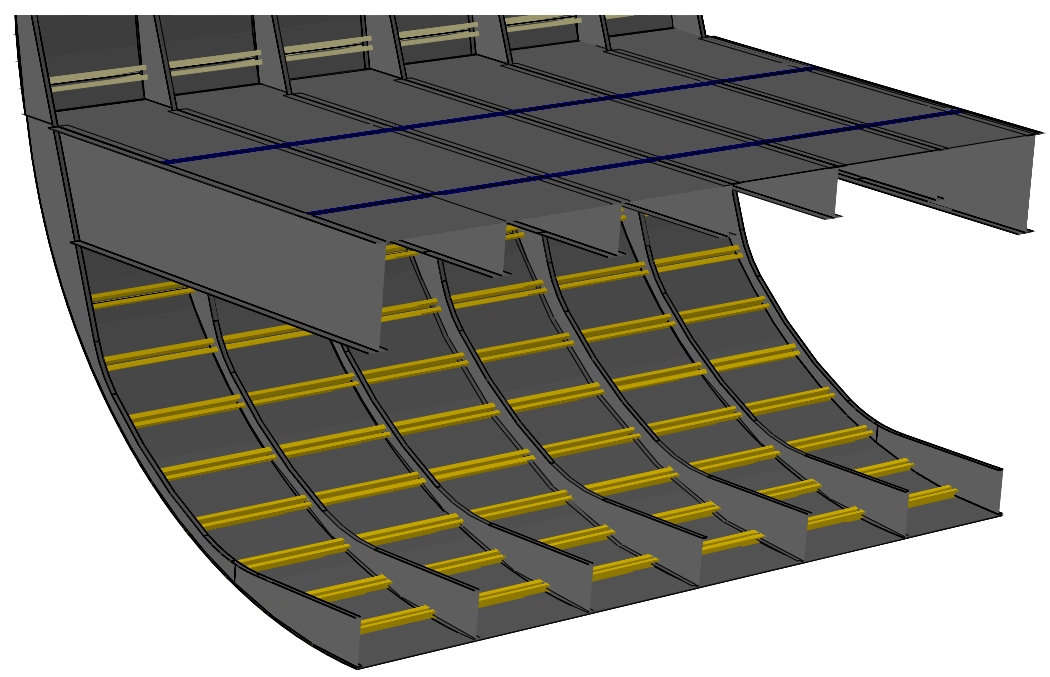

Figure 9: Detail of the lower aircraft structures.

Windows were also added to the model with simplified right-angled corners and the associated frame stiffeners. Following other authors' approach, rivets and fasteners throughout the fuselage are modeled as rigid connectors in the software [5, 27], not considering failure and damage in these elements. Other complex geometry and features, including cutouts, joints and doublers were excluded from the model, since their implementation would heavily increase the computational cost while not significantly affecting the overall behavior of the model. The 1530 liters of water filling the tank were considered by adding point inertias distributed inside the tank, thus neglecting the water sloshing effects produced in the experimental test.

While the general fuselage dimensions were obtained from technical drawings [28], the final plate thicknesses, cross-section profiles and sectional inertias were obtained through an iterative calibration process considering known static and dynamic simulations given the lack of data in the literature. These values were empirically adjusted seeking the closest resemblance to the experimental results in terms of mass, acceleration and velocity data as well as the crash dynamics of the main structures. Floor spars consist 
of I-beams with a web of $175 \mathrm{~mm}$ and $80 \mathrm{~mm}$ wide flanges; except for those at FS 420 and FS 500A which have a web of $350 \mathrm{~mm}$. Frames are Z-sectioned profiles with a flange of $20 \mathrm{~mm}$ and a variable web ranging from $60 \mathrm{~mm}$ to $165 \mathrm{~mm}$; whereas the Omega-shaped stringers have a width of $29 \mathrm{~mm}$, a base of $23 \mathrm{~mm}$, and $12 \mathrm{~mm}$ wings. Table 4 also offers a detailed list of the thicknesses and inertia values adopted that yielded the closest response to the experiments.

\begin{tabular}{lrcc}
\hline Item & Thickness $(\mathrm{mm})$ & Profile section & Inertia $\left(\mathrm{cm}^{4}\right)$ \\
\hline Fuselage skin & 2.0 & - & - \\
Floor & 2.0 & - & - \\
Fuel tank & 0.8 & - & - \\
\hline Floor spar & 2.5 & $\mathrm{I}$ & 417.924 \\
Frames (thin) & 3.0 & $\mathrm{Z}$ & 10.801 \\
Frames (thick) & 3.0 & $\mathrm{Z}$ & 56.851 \\
Stringers & 2.0 & Omega & 3.328 \\
\hline
\end{tabular}

Table 4: Geometrical properties of significant fuselage structures.

The mesh sizes were selected seeking to obtain the best trade-off between computational time and accuracy, always seeking the most realistic performance of the main aircraft structures. A total of 77289 nodes and 65391 elements compose the finite element model of the fuselage section, with 2863 beam elements, 43328 shell elements and 19200 solid elements. The components from the hybrid energy absorbers require finer meshes than those of the main structures as to obtain an accurate fold formation, reducing the mesh seed dimension by one order of magnitude; increasing overall number of elements increases over 200000 in the case of the square-sectioned design, with similar numbers for the circular tube. An image of the fuselage section's mesh is also shown in figure 7. The total number and type of elements for each part of the specimen are listed in table 5 .

The tested section has a total mass of $3980 \mathrm{~kg}$, whereas the tuned finite element model weighs $3890 \mathrm{~kg}$, a difference less than $3 \%$ due to the adjustment of structural dimensions and thicknesses. A detailed list of the mass of each part is provided in table 6 . When the hybrid energy absorbers are added, the mass of the fuselage increases by $1.4 \mathrm{~kg}(0.03 \%)$, corresponding to $0.35 \mathrm{~kg}$ from each device.

For the impacting surface, a solid block with a thickness of $100 \mathrm{~mm}$ and similar dimensions to those of the wood used in the test was included. General contact properties were also added to the model, with a friction coefficient of 0.06 . 


\begin{tabular}{llrr}
\hline Item & Element type & Element no. & Avg. size (mm) \\
\hline Fuselage & S4R & 9959 & 75 \\
Fuel tank & S4R & 3150 & 50 \\
Frames & S4R & 30219 & 20 \\
Stringers & B31 & 2863 & 75 \\
Impacting surface & C3D8R & 19200 & 50 \\
Occupants and seats & Point masses & 20 & - \\
\hline HEA tube & S4R & 19584 & 7 \\
HEA plates & S4R & 18880 & 3 \\
HEA foam & C3D8R & 101008 & 3 \\
\hline
\end{tabular}

Table 5: Type, number and size of the finite elements used.

\begin{tabular}{lrr}
\hline Item & Test article & Simulation \\
\hline Fuselage & 598 & 550 \\
Tank & 1700 & 1640 \\
Occupants, seats and miscellaneous & 1692 & 1700 \\
\hline Total weight & 3980 & 3890 \\
\hline
\end{tabular}

Table 6: Comparison of masses (in $\mathrm{kg}$ ) between the test article and the computer model.

Four different crash test scenarios and a static case with internal pressure are presented in the following paragraphs, with the latter only being used for validation purposes. The impact against solid ground is used both for validation and obtaining crashworthiness metrics. Moreover, once the model is validated, an additional hard-landing scenario of the fuselage without the auxiliary fuel tank is developed and analyzed. The behavior and collapse mechanisms of the fuselage section differ when the tank is removed from the sub-cargo area, as the tank can dissipate a significant amount of kinetic energy through plastic deformation [29]. The no-tank scenario is also of significant interest considering it is more common than that with an auxiliary fuel tank. The two hard-landing tests are repeated with the vertical energy absorbing struts, with and without the auxiliary fuel tank, as to understand their effect on the global aircraft crash mechanics.

\subsection{Analysis settings}

Two different types of analyses are performed. The first one is a static case with an internal pressure of $45 \mathrm{kPa}$. The fuselage section model is fixed at the floor spars and complies with a symmetry boundary condition at the top of the fuselage. This load case is only used for the validation of the developed numerical model, comparing deformation values with the expected from existent literature. 
Later on, for the studied hard-landing scenarios, the impact conditions match those of the experimental test, with an initial impact velocity of $9.144 \mathrm{~m} / \mathrm{s}$.

\section{Results and discussion}

\subsection{Internal pressure static load}

The first result used for the validation of the developed model are obtained from a static loading case with internal pressure on a fuselage without the auxiliary fuel tank. According to the results presented in the report from Jeong et al. [30], the maximum radial displacement under the considered load should be slightly under $4 \mathrm{~mm}$. In the model studied, the total displacement is that of 3.8 millimeters, thus within the experimental boundary. The results are shown in figure 10 .

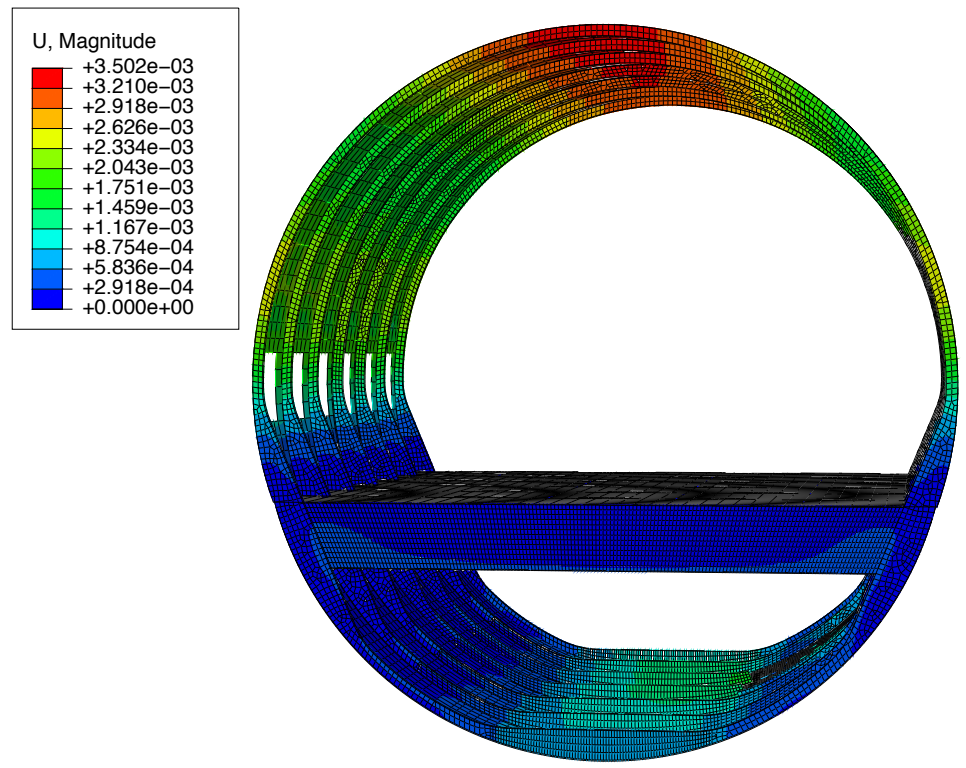

Figure 10: Absolute displacements obtained in the static load case. All values in meters.

\subsection{Hard landing impact}

The fuselage was tested and used for validation of the finite element model developed. After the simulation of the hard-landing scenario, different considerations were made to assess whether the finite element model had a similar behavior to the experimental test specimen.

\subsubsection{Fuselage with auxiliary fuel tank}

A qualitative comparison between the experimental and numerical results was performed at different time values during the simulation to assess the similarities in the collapse of the numerical model and the experimental specimen. Figure 11 shows three 
views of both at 20, 60 and $100 \mathrm{~ms}$. The images show significant resemblances between the collapse mechanisms of the numerical and analytical models, with similar locations of the frames' plastic hinges, the asymmetry caused by the presence of the cargo door and an almost equal deformation of the sub-floor structures.

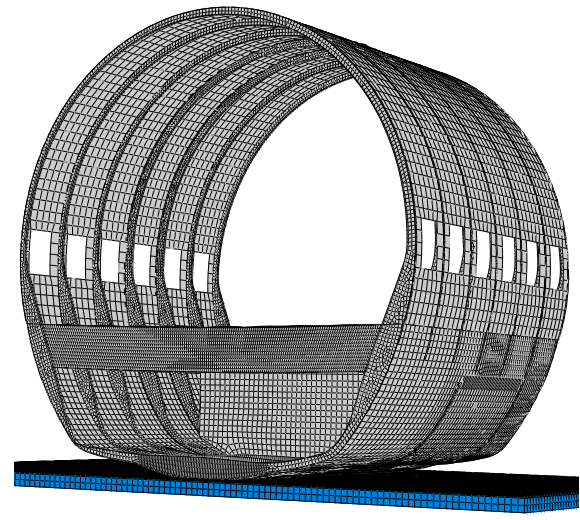

(a) Front view of FEM at $20 \mathrm{~ms}$.

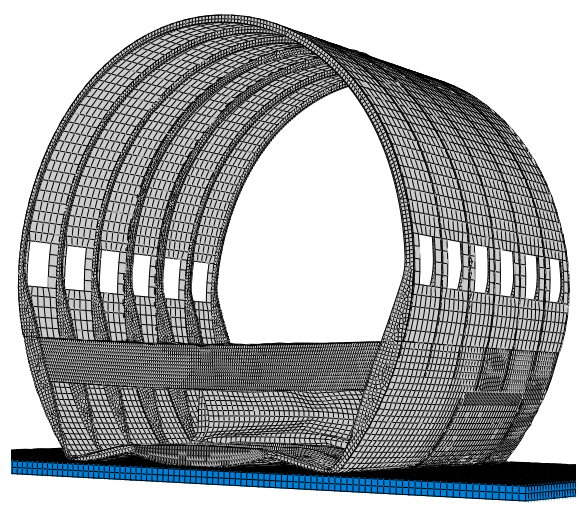

(c) Front view of FEM at $60 \mathrm{~ms}$.

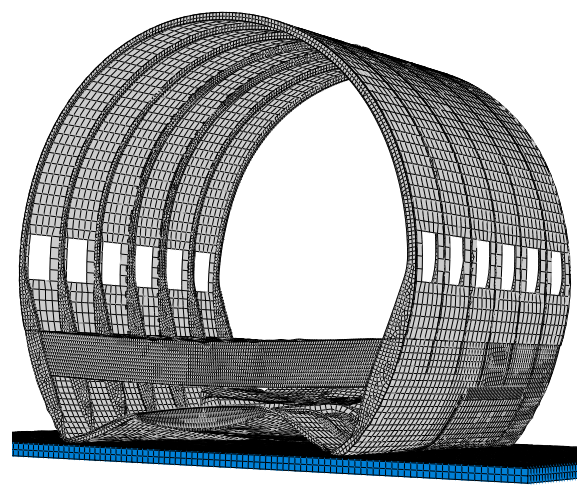

(e) Front view of FEM at 100 ms.

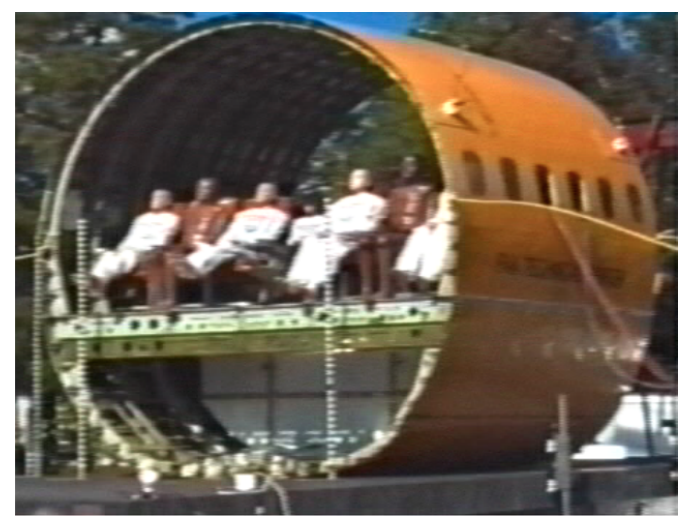

(b) Front view of specimen at $20 \mathrm{~ms}$.

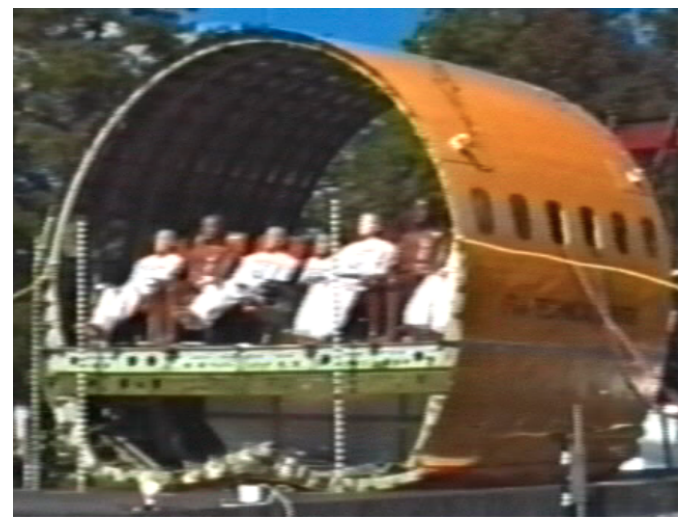

(d) Front view of specimen at $60 \mathrm{~ms}$.

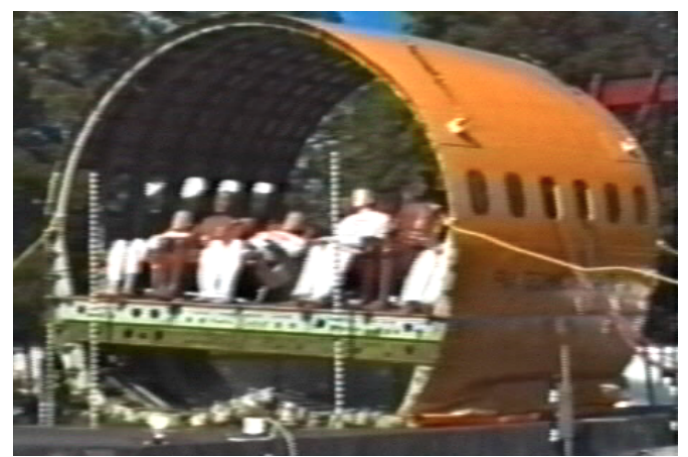

(f) Front view of specimen at $100 \mathrm{~ms}$.

Figure 11: Comparison between the real [15] and numerical specimens at $20 \mathrm{~ms}, 60 \mathrm{~ms}$ and $100 \mathrm{~ms}$.

Furthermore, the final deformation on both the right and left sides of the floor was measured. The asymmetry of the fuselage due to the presence of the cargo door yields a maximum displacement of $58 \mathrm{~cm}$ compared to the $55 \mathrm{~cm}$ obtained experimentally on the right side. For the left side, the numerical displacement is $52.7 \mathrm{~cm}$, whereas the test 
specimen yielded a value of $52.5 \mathrm{~cm}$.

The velocity and acceleration responses were also monitored for both sides of the fuselage floor. The graphs in figures 12 and 13 show the comparison between the velocity and acceleration histories for both locations at the two measured locations. Accelerations were filtered with a 48-Hz four-pole Butterworth low-pass filter forwards and backwards as performed by Fasanella and Jackson [15], whereas velocities are not filtered as it would alter the shape of the curves. All four graphs offer a good comparison between the experimental and numerical results. Velocities show the correct trends, although a minor discordance is observed as the right side slows down quicker given the presence of the cargo door. Concerning accelerations, the numerical data also yields comparable results to those obtained from the experiment despite the existence of some time shift has been observed, more severe at the left side. However, the numerical peak acceleration of 27 g's nearly matches the experimental peak of $26 \mathrm{~g}$ 's at location 1, while peak values at location 2 are 42 g's and 36 g's for the numerical and experimental tests respectively. To further examine the fitness of the numerical model, the metrics from Sprague and Geers [31] are computed as to assess the magnitude $M_{\mathrm{SG}}$ and phase $P_{\mathrm{SG}}$ errors on the responses from the simulation. The results, displayed in table 7 , show error values under $15 \%$ for the magnitude metric and discordances under $30 \%$ between phases, within the limits for accepting the numerical model as a validated simulation [32].

\begin{tabular}{lcc}
\hline & \multicolumn{2}{c}{ Error metric } \\
\cline { 2 - 3 } & $M_{\mathrm{SG}}$ & $P_{\mathrm{SG}}$ \\
\hline Location 1 & 0.14 & 0.28 \\
Location 2 & 0.12 & 0.26 \\
\hline
\end{tabular}

Table 7: Magnitude and phase errors [31] between experimental and numerical acceleration responses.

Finally, the model energies are monitored to ensure that the analysis settings do not induce high artificial energy values for stabilization and convergence purposes (see figure 14). For this model and impact conditions, the artificial energy is less than $9 \%$ of the internal energy of the model, thus being well under the recommended maximum of $10-15 \%$ for similar crashworthiness numerical simulations [26].

Additionally, the results obtained from the hard-landing scenario have been compared to the numerical validation from Fasanella and Jackson [15], which display a similar fitness of the acceleration and velocity graphs to the ones here presented. Considering this 


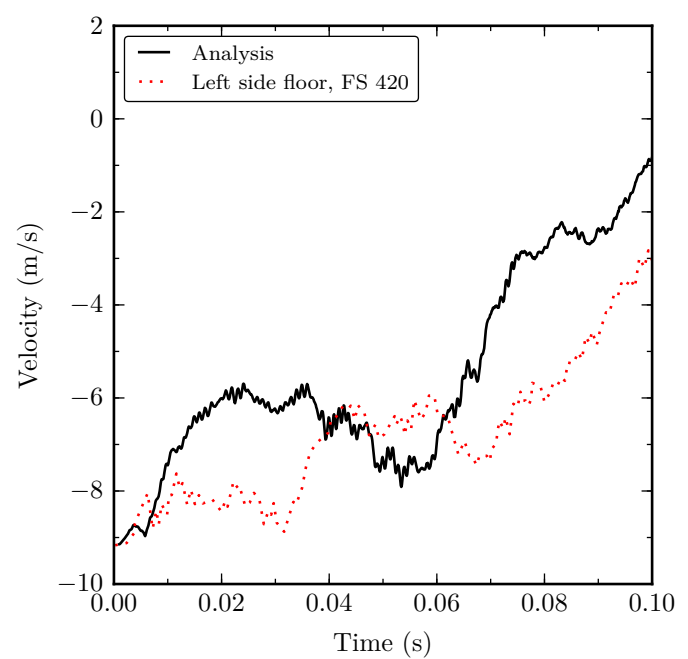

(a) Left floor velocity (location 1).

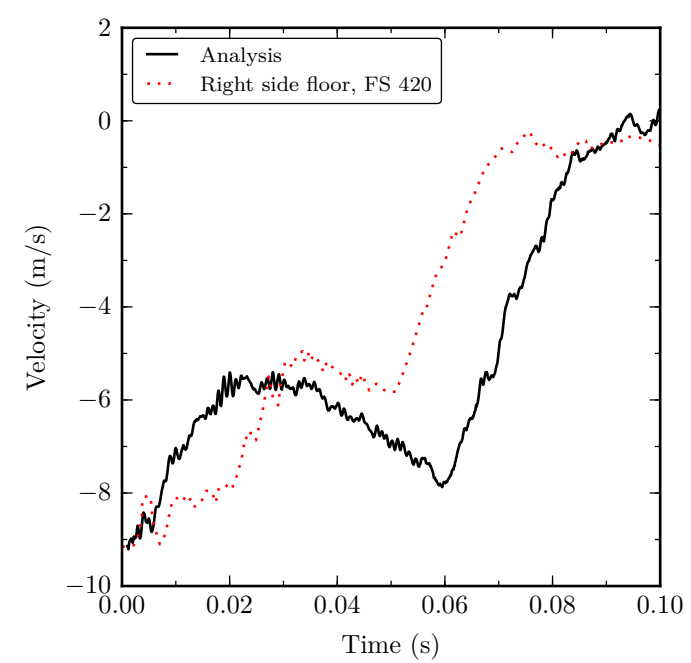

(b) Right floor velocity (location 2).

Figure 12: Left and right floor velocities. Experimental and numerical results.

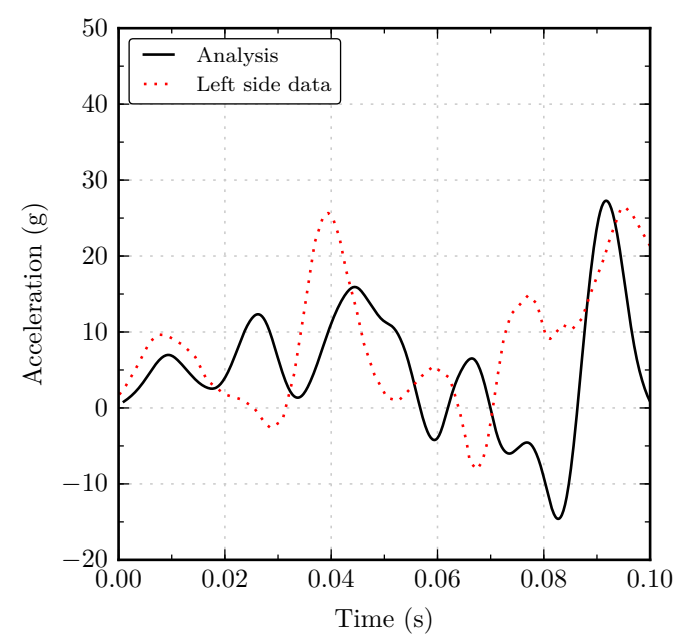

(a) Left floor acceleration (location 1).

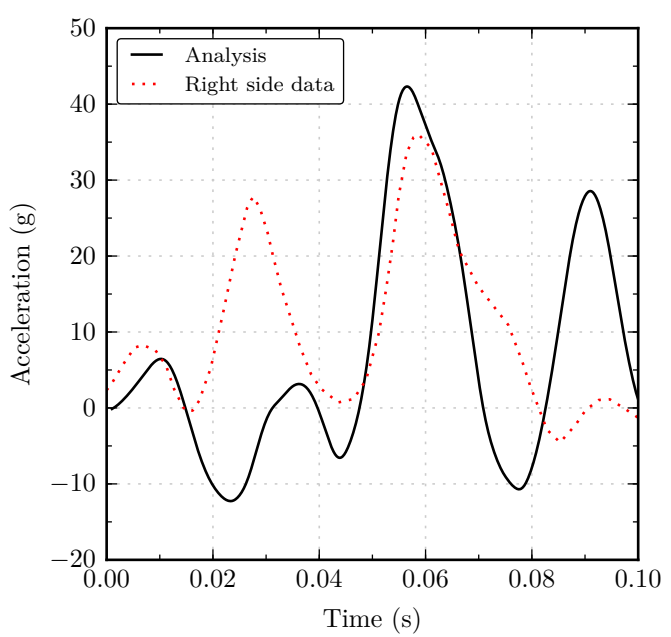

(b) Right floor acceleration (location 2).

Figure 13: Left and right floor accelerations. Experimental and numerical results 


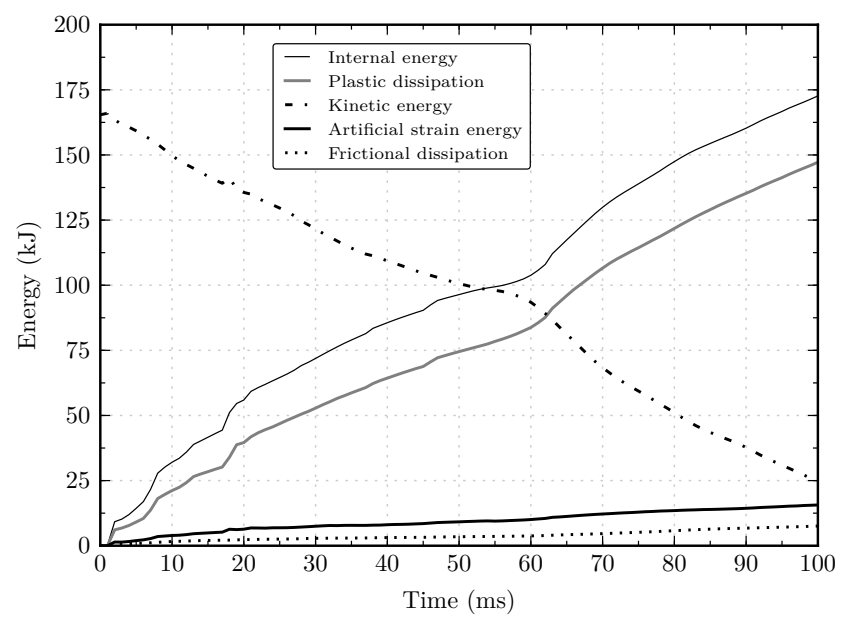

Figure 14: Model energies throughout the simulation.

and a final examination of the static and the hard-landing simulation results, the numerical model here proposed is regarded as a validated specimen with a similar dynamic behavior and crash evolution as the representative fuselage section studied.

\subsubsection{Fuselage without auxiliary fuel tank}

After examining the results obtained from the original fuselage section, in which the auxiliary fuel tank is responsible for absorbing nearly $60 \mathrm{~kJ}$ through plastic dissipation, this component was removed from the aircraft and the simulation is again analyzed. Moreover, in the hard-landing with the fuel tank, the fuselage nearly comes to a halt within the 100-millisecond simulation. However, that is not the case for this scenario, thus requiring the simulation to run for $150 \mathrm{~ms}$ to capture the deformations in the latest parts of the process.

A graphic comparison between both resulting post-test configurations shown in figures 19a and 19c elucidates the effect of the fuel tank as part of the fuselage. The presence of the fuel tank not only reduces the deformation of the lower half of the main frames, but it also avoids the impact of the latter with the floor beams. With the tank removed, the maximum deformation on the left increases from $52.7 \mathrm{~cm}$ to $69.8 \mathrm{~cm}$, while the right side also increases is displacement by over $17 \mathrm{~cm}$.

Moreover, vertical accelerations are monitored at the four selected locations as to assess the effect of removing the tank on the crashworthiness of the craft. Figure 15a combines the vertical acceleration data extracted for this impact scenario at all four locations, in which the effect of the collision between the frames and the passenger floor beams becomes apparent with the high acceleration peaks neighboring 90 g's observed approximately $100 \mathrm{~ms}$ into the simulation. Furthermore, figure $15 \mathrm{~b}$ offers their depiction 


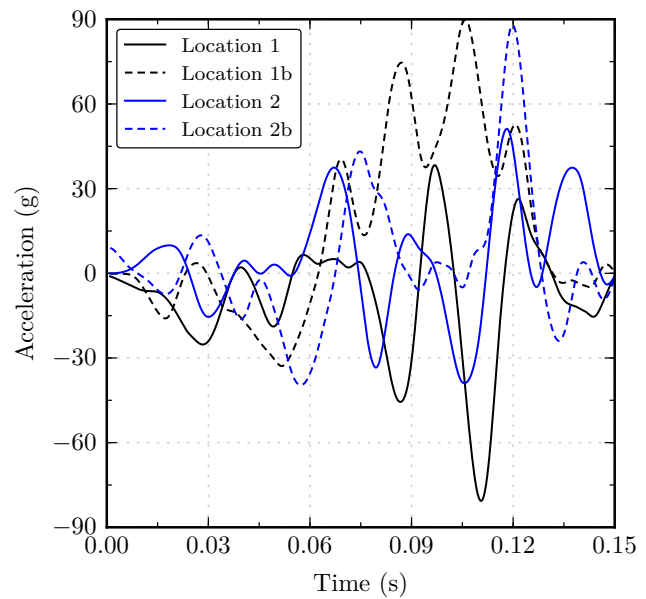

(a) Vertical accelerations at measured locations.

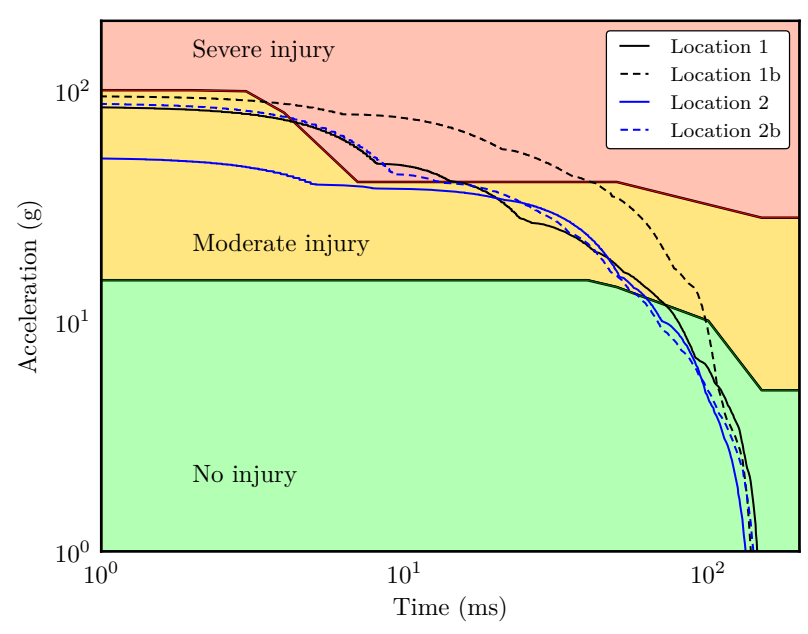

(b) Eiband diagram for vertical accelerations at measured location.

Figure 15: Vertical accelerations and depiction in Eiband diagram for fuselage without the auxiliary fuel tank and without energy absorbers.

in an Eiband diagram, confirming the plausible harmful effects for the passengers in such scenario. This diagram exhibits a depiction of the vertical accelerations at the floor level, although the loads experienced by passengers at those locations in a real event would be lower due to factors as the usage of seat restraints and cushion damping. Only location 2 exhibits a profile within the moderate injury region, while all others, and especially location $\mathbf{1 b}$, are well into the severe injury region.

\subsection{Effect of the hybrid energy absorbers}

The vertical struts were added to the model and the data obtained was compared to that from the original fuselage section. The different tube cross-sections presented in figure 5, as well as variation in their position are first tested for a fuselage section without the auxiliary fuel tank, given that the crashworthiness enhancement of this configuration is more critical. Later on, the design offering the best results is implemented in the fuselage with the fuel tank and results are compared to the unmodified aircraft design.

In order to assess the improvement obtained from the usage of the energy absorbers, the Eiband diagram is used together with the acceleration responses for two locations on the left side of the fuselage, $\mathbf{1}$ and $\mathbf{1 b}$ (see figure 7), and the two symmetrically opposed on the right side, $\mathbf{2}$ and $\mathbf{2 b}$.

\subsubsection{Fuselage without auxiliary fuel tank}

Three different enhancement cases are considered for improving the crashworthiness of the fuselage without fuel tank, simulating the aircraft's hard landing with square and 
circular HEAs added 2.04 meters apart in the transversal direction and with square HEAs separated $2.2 \mathrm{~m}$ (the latter case referred to as "wide configuration").

After computing all three scenarios and comparing the post-impact deformation, similar patterns are observed. A closer examination to the collapse evolution of the main structures reveals how the collision with the ground crushes the sub-cargo area after 20 $\mathrm{ms}$, as shown in figure 16a. Another $20 \mathrm{~ms}$ into the simulation, the main frames experience high localized deformation at the struts' insertion areas, forming two plastic hinges on each frame that allow for a flattening of this region (see figure 16b). Although the lower part of the struts undergoes some deformation before this point, it is only after $50-60 \mathrm{~ms}$ that absorbers fully collapse under post-buckling conditions, developing between one or two folds as seen in figure 16c. Finally, figure 16d reveals how the floor spars bend near the middle section while struts crushing continues until the specimen completely comes to a halt.

Further analysis of the results is done at the HEA level, first comparing the resulting crushed specimens. The circular section in figure 17a starts its collapse with a mushroom deformation mode [33], originated due to the outwards deformation used as a trigger on the upper edge, followed by a diamond collapse mode [34]; while in the case of the square tube only the inextensional mode appears [35]. The resulting force-displacement curves, presented in figure 18, elucidate the behavior offered by both energy absorbers proposed under location $\mathbf{1 b}$ filtered with a SAE 600 filter. The crash response from the square HEA shows a low initial peak of $66 \mathrm{kN}$ for the initiation of the strut's collapse, followed by a crushing force in the range of $30-45 \mathrm{kN}$ throughout most of the crushing. However, after $90 \mathrm{~ms}$ the vertical strut ceases to absorb and dissipate energy as the fuselage's cargo compartment stops collapsing, amounting to circa $3 \mathrm{~kJ}$ of absorbed energy. In the case of the circular tube, the initial crushing force nearly reaches $85 \mathrm{kN}$, which may be the cause for the higher accelerations obtained with this configuration at the earlier stages of the crushing. However, as a standalone component, the circular HEA absorbs $15 \%$ more energy through plasticity than the square counterpart, nearly reaching $4.5 \mathrm{~kJ}$.

As previously mentioned, a structural arrangement featuring HEAs $16 \mathrm{~cm}$ further apart is also considered. Although the absorbers do collapse and develop a similar number of folds as in the narrower configuration, the overall crashworthiness improvement is reduced. Acceleration peaks are higher than in the other two scenarios for three of the locations, even surpassing the original acceleration peak at location $\mathbf{2}$ as presented in table 8, thus discarding this configuration as the path towards crashworthiness enhancement. It 

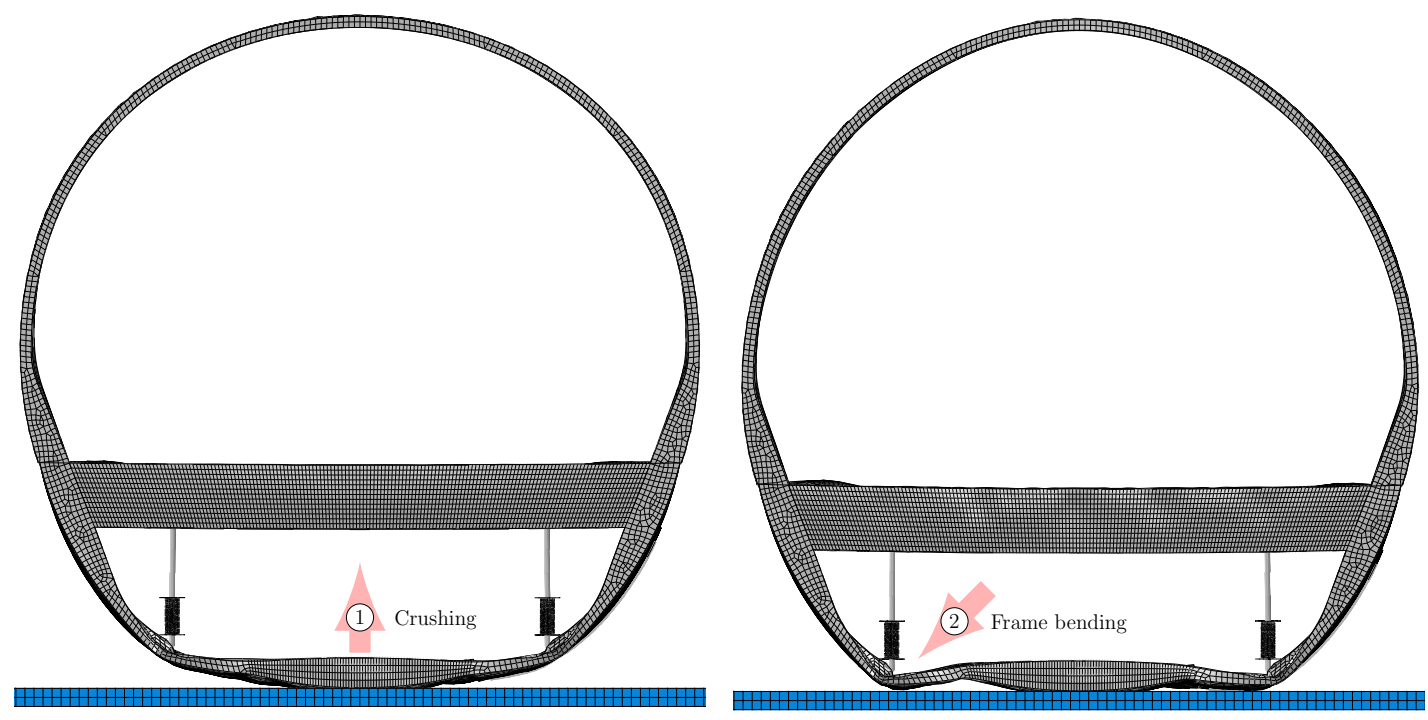

(a) Fuselage $20 \mathrm{~ms}$ after collision. Crushing of (b) Fuselage $40 \mathrm{~ms}$ after collision. Frame bendthe sub-cargo area. ing and formation of plastic hinges.
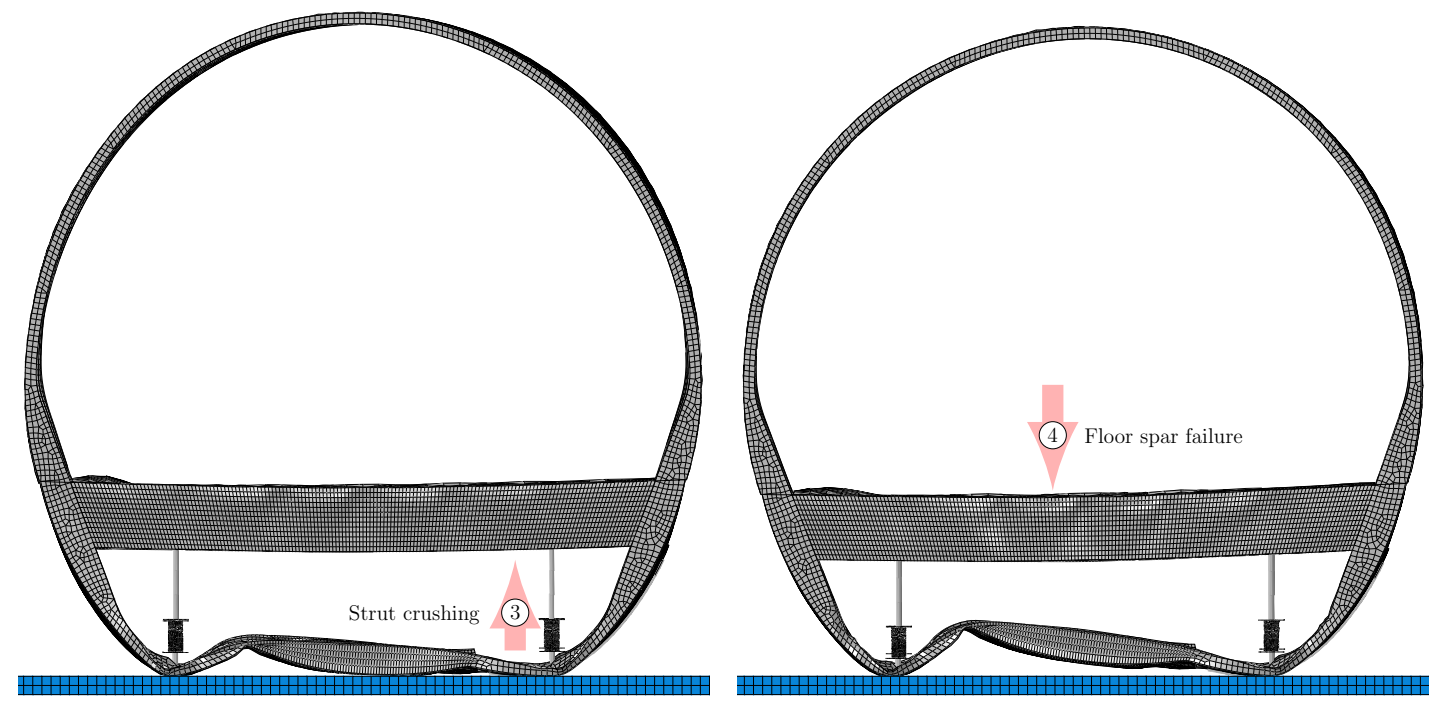

(c) Fuselage $60 \mathrm{~ms}$ after collision. Strut crush- (d) Fuselage $80 \mathrm{~ms}$ after collision. Collapse of ing. the floor spars.

Figure 16: Aircraft collapse evolution of main structures for the fuselage enhanced with square HEAs. 


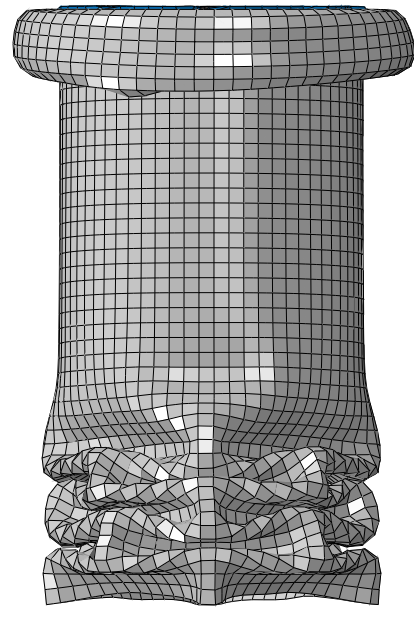

(a) Circular HEA.

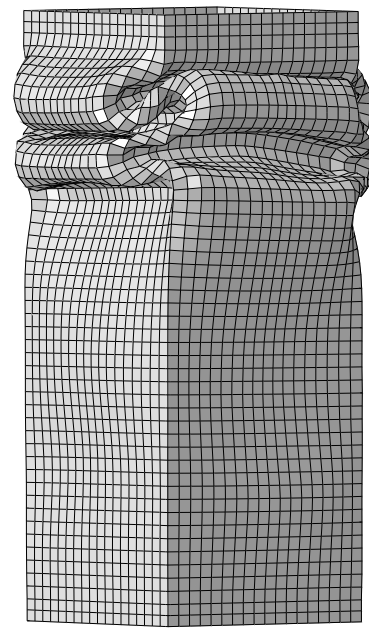

(b) Square HEA.

Figure 17: Post-test deformation of square and circular HEAs under location $\mathbf{1 b .}$

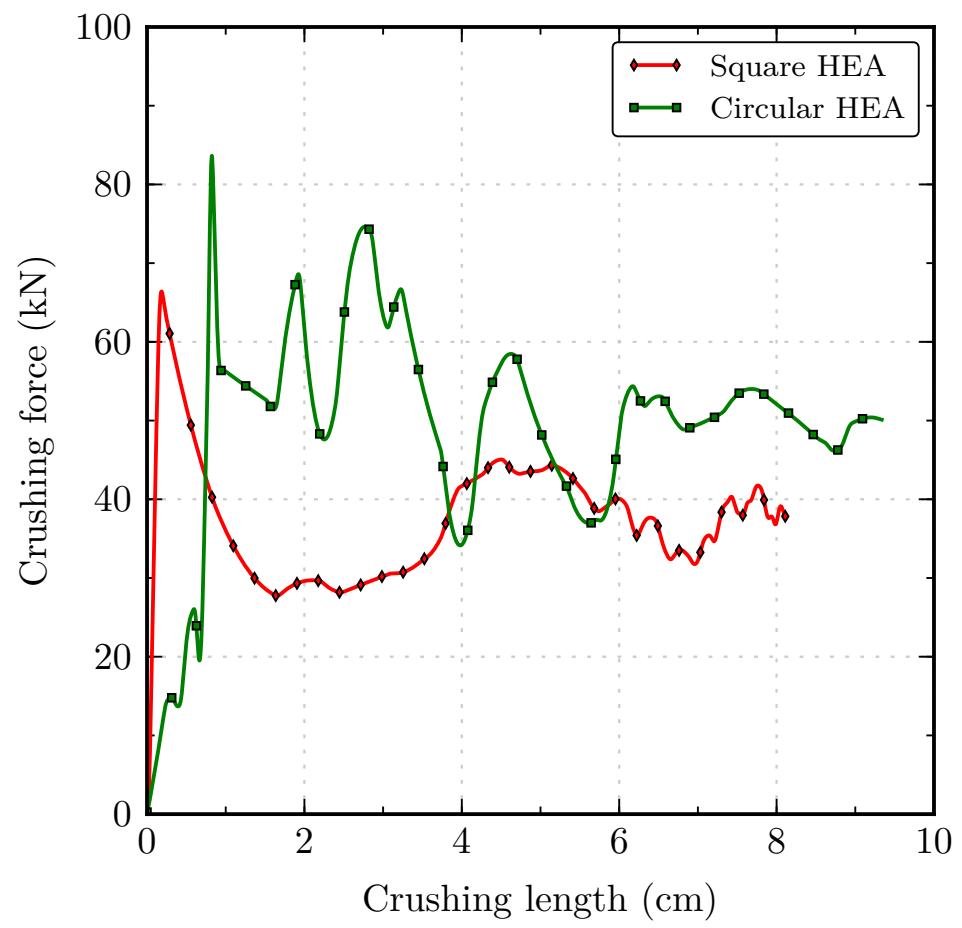

Figure 18: Response of circular and square HEAs from figure 17 under location $\mathbf{1 b .}$ 
is only at location $\mathbf{2 b}$ where the responses better all other cases considered, although the injury rating is still within the severe injury region (see figure $21 \mathrm{~d}$ ).

Figure 19 offers the post-test final deformation for two fuselage sections without the auxiliary fuel tank, with and without energy absorbers. When comparing figures 19a and $19 \mathrm{c}$, it is clear that the absence of a fuel tank results in a higher deformation of the sub-cargo area. However, the hybrid energy absorbers not only ensure a higher sub-cargo area after the impact, but they also delay the impact of the lower frame structures with the floor spars observed in figure 19c, and therefore, lower accelerations are transmitted to the passengers in the final $50 \mathrm{~ms}$ of the crushing process (figure 20). The location where the plastic hinges form in the main frames is also affected, as bending occurs where the struts are inserted rather than on the outer regions of the frame. Consequently, the frames' plastic dissipation capabilities are better exploited, increasing this value from the original $76 \mathrm{~kJ}$ to $122 \mathrm{~kJ}$ for the structural configuration including square-sectioned HEAs.

The acceleration graphs from figures 20 and 21 compare the accelerations and the resulting Eiband diagrams for the four fuselage sections considered. A common trend is observed for all enhanced sections, where the earliest $50-60 \mathrm{~ms}$ show that fuselages with HEAs undergo higher accelerations than the original configuration, caused by the presence of the struts initiating the collapse process.

As the crushing continues, the original specimen bottoms-out and the lowest section of the frames hits the underfloor beams, resulting in acceleration peaks neighboring $90 \mathrm{~g}$ 's for three of the monitored locations as shown in table 8 . However, since the sections with energy absorbers experience a more controlled collapse and the energy absorbers dissipate circa $10 \mathrm{~kJ}$ of the fuselage's kinetic energy through plastic deformation, the acceleration peaks are lowered considerably, obtaining final values reduced by up to $50 \%$ compared to the original specimen.

Moreover, the contribution offered by the energy absorbers is ever best perceived in the Eiband diagrams from figures 20b, 20d, 21b and 21d. In the scenario with no vertical struts, the accelerations experienced on three of the locations can lead to severe injuries, mainly caused during the latest stages of the impact. However, in the enhanced sections, the injuries are consistently drawn towards the moderate injury region due to the more stable collapse mechanism obtained and the energy dissipated by the energy absorbers. 


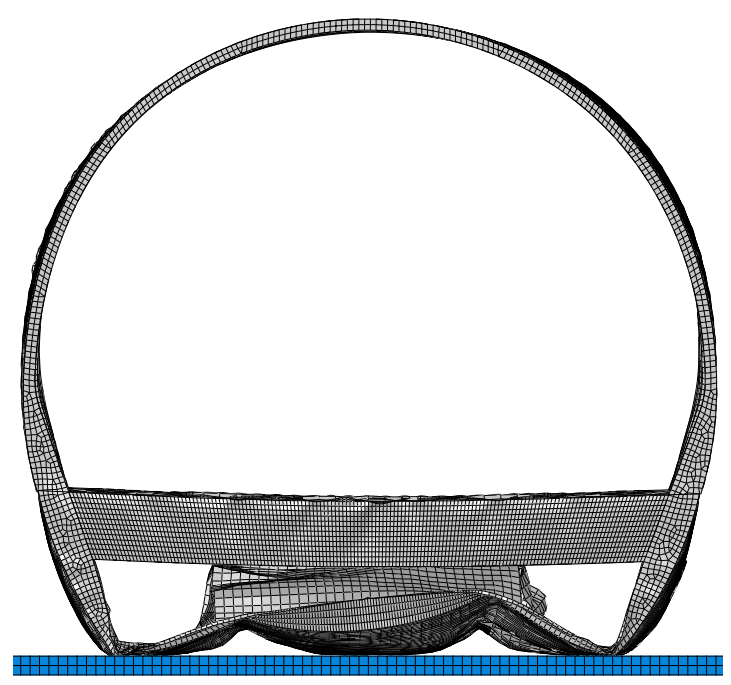

(a) Fuselage with auxiliary tank without energy absorbers.

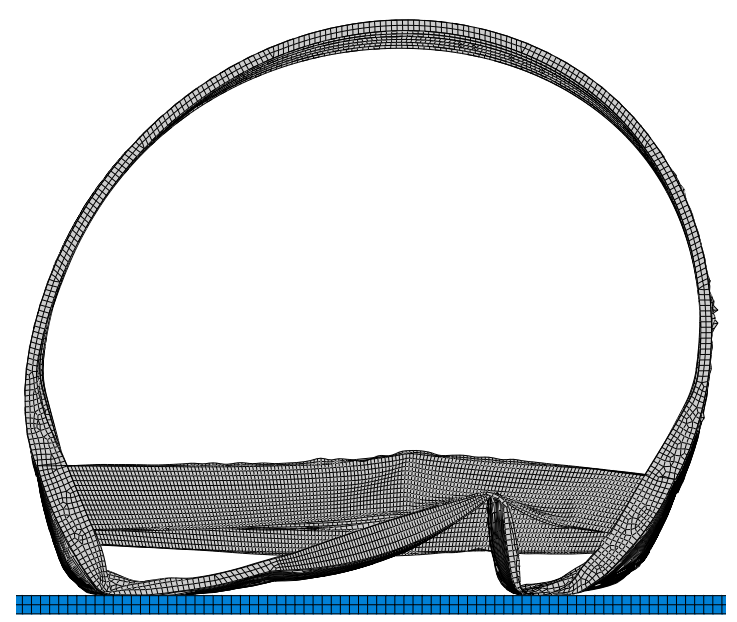

(c) Fuselage without auxiliary fuel tank without energy absorbers.

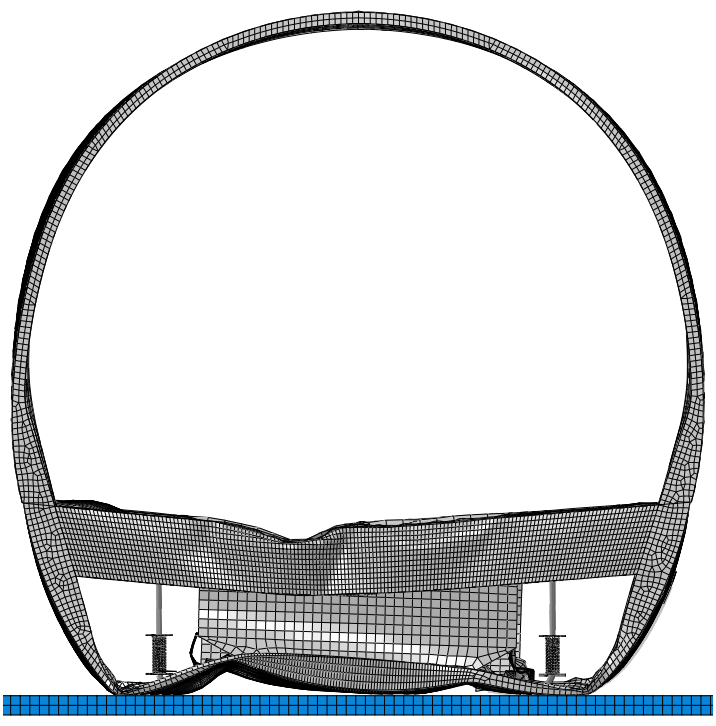

(b) Fuselage with auxiliary tank with hybrid energy absorbers.

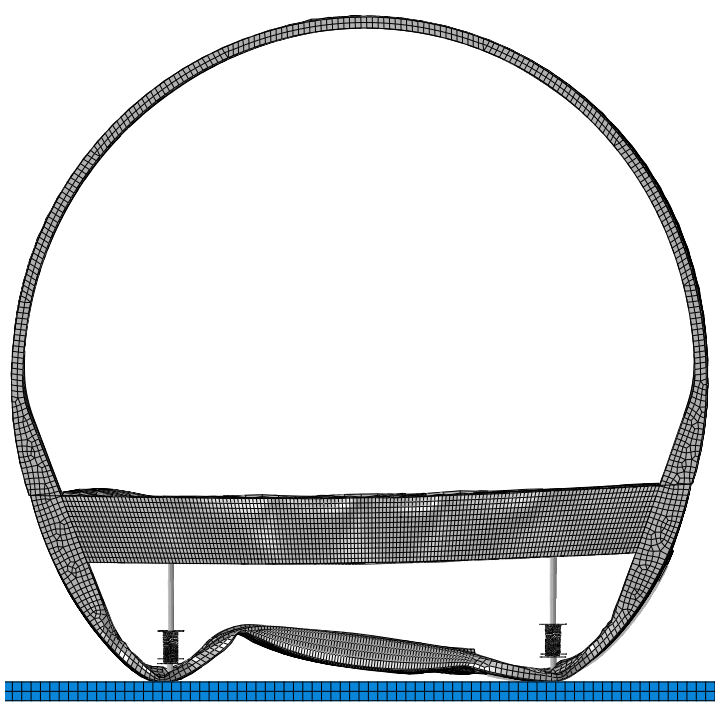

(d) Fuselage without auxiliary fuel tank with hybrid energy absorbers.

Figure 19: Deformation of the specimen with and without the auxiliary fuel tank, before and after implementation of hybrid energy absorbers. 


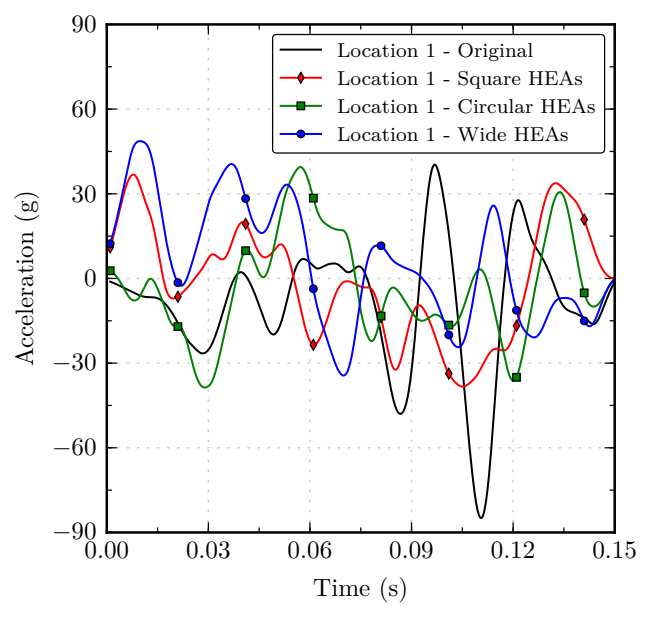

(a) Vertical accelerations at location $\mathbf{1 .}$

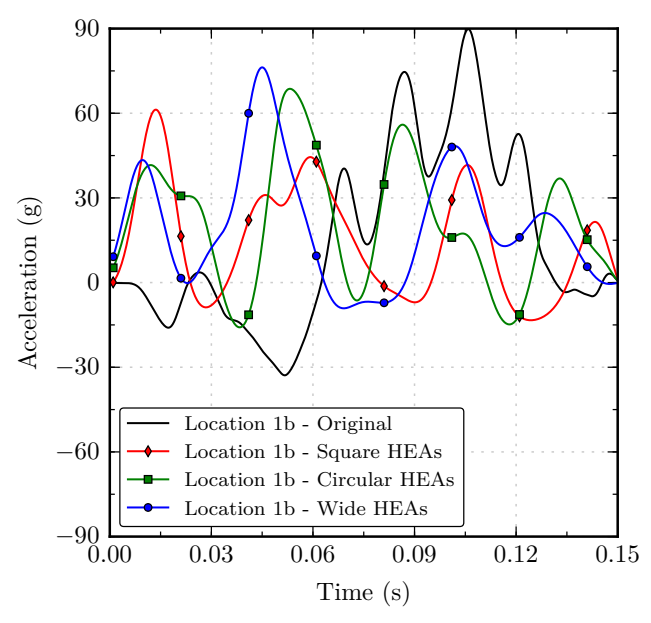

(c) Vertical accelerations at location $\mathbf{1 b}$.

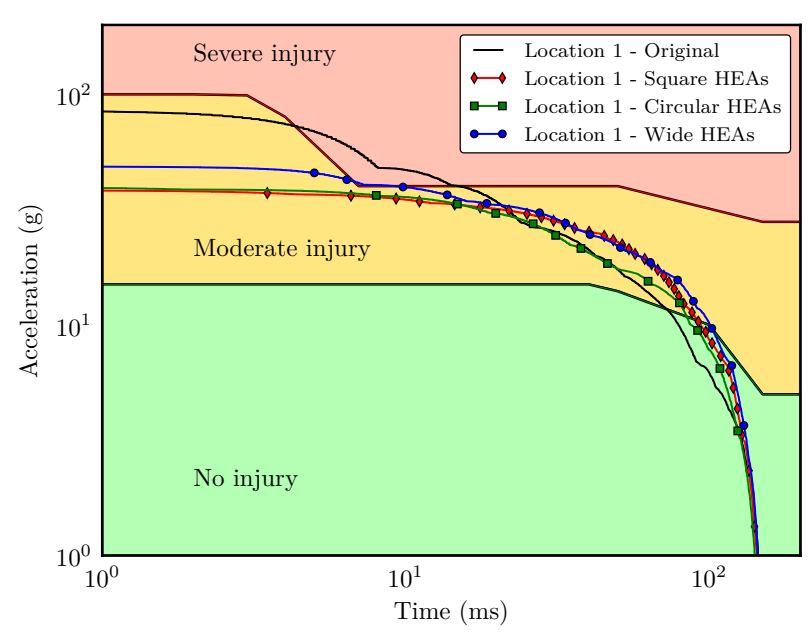

(b) Eiband diagram for location $\mathbf{1}$.

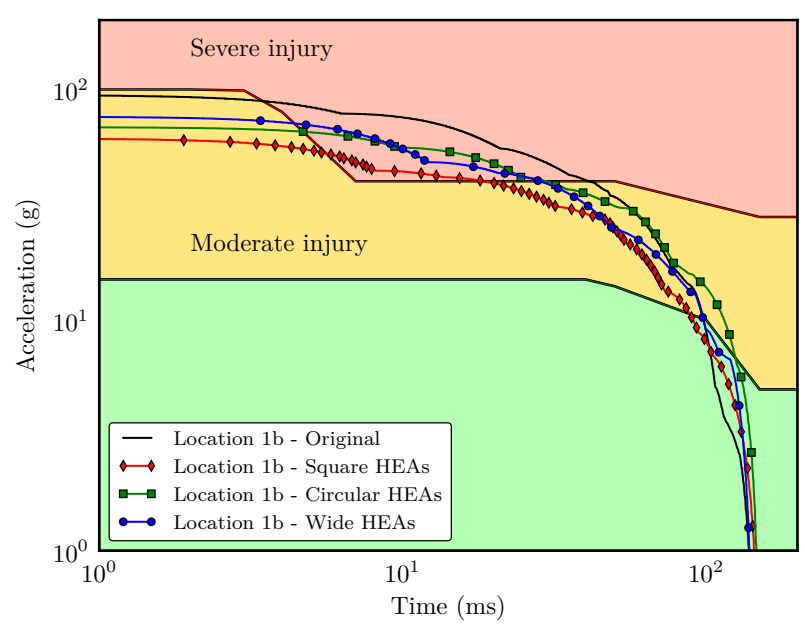

(d) Eiband diagram for location $\mathbf{1 b}$.

Figure 20: Vertical accelerations and depiction in Eiband diagram at locations $\mathbf{1}$ and $\mathbf{1 b}$. Fuselage without the auxiliary fuel tank, with and without energy absorbers. 


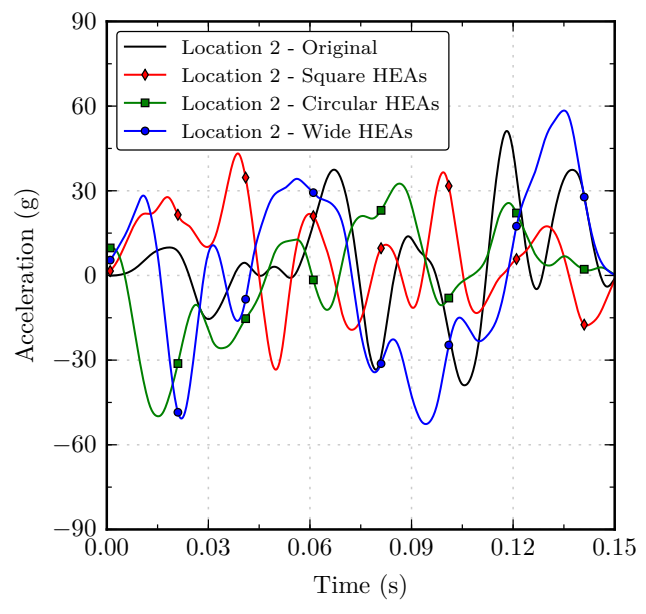

(a) Vertical accelerations at location $\mathbf{2}$.

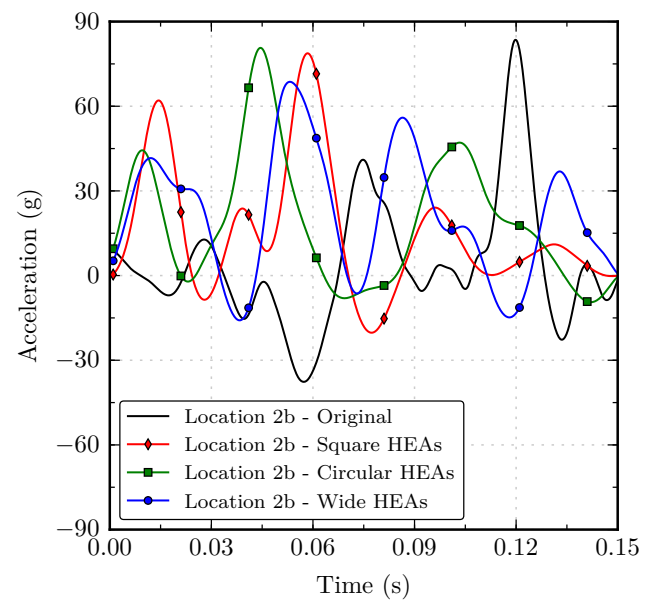

(c) Vertical accelerations at location $\mathbf{2 b}$.

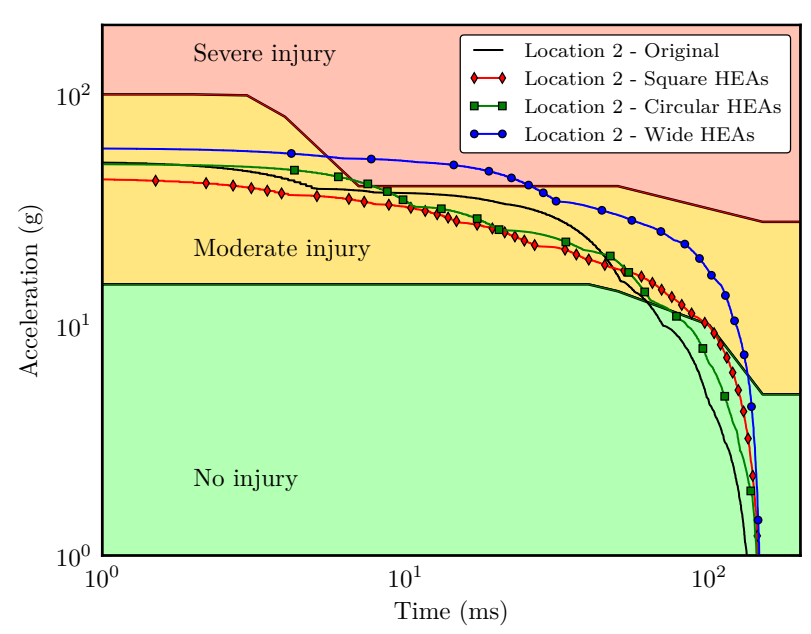

(b) Eiband diagram for location 2.

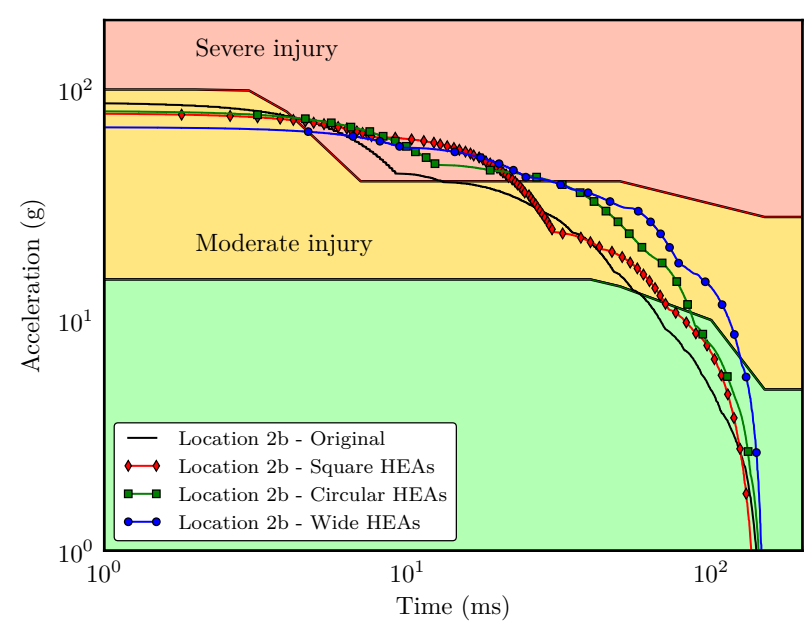

(d) Eiband diagram for location $\mathbf{2 b}$.

Figure 21: Vertical accelerations and depiction in Eiband diagram at locations $\mathbf{2}$ and $\mathbf{2 b}$. Fuselage without the auxiliary fuel tank, with and without energy absorbers. 


\begin{tabular}{lrrrrrrrr}
\hline & \multicolumn{2}{c}{ Original fuselage } & \multicolumn{2}{c}{ Square HEA } & \multicolumn{2}{c}{ Circular HEA } & \multicolumn{2}{c}{ Wide config HEA } \\
\cline { 2 - 9 } Location & Max $(\mathrm{g})$ & Avg $(\mathrm{g})$ & $\operatorname{Max}(\mathrm{g})$ & $\operatorname{Avg}(\mathrm{g})$ & $\operatorname{Max}(\mathrm{g})$ & $\operatorname{Avg}(\mathrm{g})$ & Max $(\mathrm{g})$ & Avg $(\mathrm{g})$ \\
\hline $\mathrm{1}$ & 84.90 & 25.08 & 38.34 & 24.88 & 39.47 & 22.37 & 48.67 & 26.76 \\
$\mathrm{1b}$ & 94.55 & 40.13 & 61.27 & 28.26 & 68.66 & 37.18 & 76.25 & 33.13 \\
\hline 2 & 51.18 & 21.64 & 43.21 & 22.08 & 49.97 & 21.82 & 58.42 & 37.38 \\
$\mathrm{2b}$ & 87.93 & 24.17 & 78.76 & 27.72 & 80.69 & 32.42 & 68.66 & 37.18 \\
\hline
\end{tabular}

Table 8: Acceleration maximums ${ }^{1}$ and averages for the fuselage without auxiliary fuel tank. Comparison between original and enhanced fuselage sections studied.

\subsubsection{Fuselage with auxiliary fuel tank}

After the assessment of the different HEA designs and placements within the craft, the square HEA is selected, maintaining the narrow configuration with a distance of 2.04 $\mathrm{m}$ between absorbers. The effect of struts on the acceleration response for the fuselage sections with the auxiliary fuel tank was analyzed and depicted in figure 22. Results from table 9 show an increased peak acceleration value at location $\mathbf{1}$, with the corresponding increase of the average acceleration for the fuselage featuring energy absorbers. However, on location $\mathbf{1 b}$ the responses differ significantly between both fuselage configurations, where the enhanced section's acceleration peak is reduced by over $12 \mathrm{~g}$ as well as decreasing the average acceleration by $40 \%$. Both data extraction points at the right side of the fuselage exhibit a bettered behavior with reduced peak accelerations, with the most noticeable improvement observed at location $\mathbf{2 b}$, where the acceleration peak decreases from over $52 \mathrm{~g}$ 's to less than $29 \mathrm{~g}$ 's as a result of adding vertical struts.

The Eiband diagrams in figures $22 \mathrm{~b}$ and $22 \mathrm{~d}$ are used to compare the plausible injuries at the locations monitored. After implementing the square HEAs to the model, the injury rating is lowered on location $\mathbf{1 b}$, even though the outcome for location $\mathbf{1}$ is more harmful given the shorter acceleration pulses. Injuries at locations $\mathbf{2}$ and $\mathbf{2 b}$ are also reduced, with a more significant effect at the latter.

\section{Conclusions}

For this research, thin-walled hybrid energy absorbers are developed to work as vertical struts under axial impact loads on fuselage aircraft structures. Rather than studying their response as standalone components, these devices are added to a 3.048-meter long

\footnotetext{
${ }^{1}$ Values in red in tables 8 and 9 correspond to the highest acceleration peak for each location between the studied configurations, whereas those in green mark the minimums.
} 


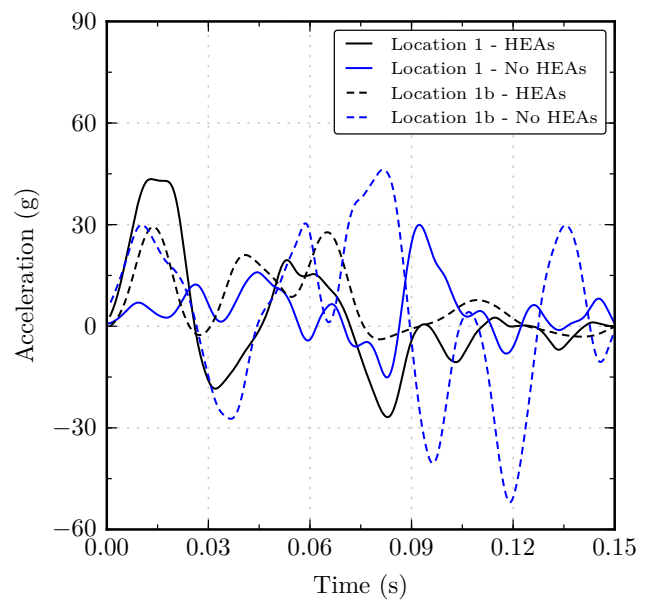

(a) Accelerations at locations $\mathbf{1}$ and $\mathbf{1 b}$.

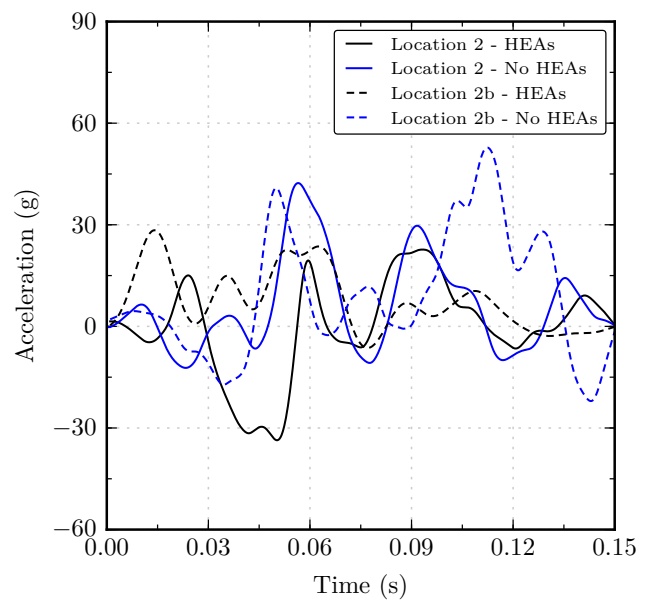

(c) Accelerations at locations $\mathbf{2}$ and $\mathbf{2 b}$.

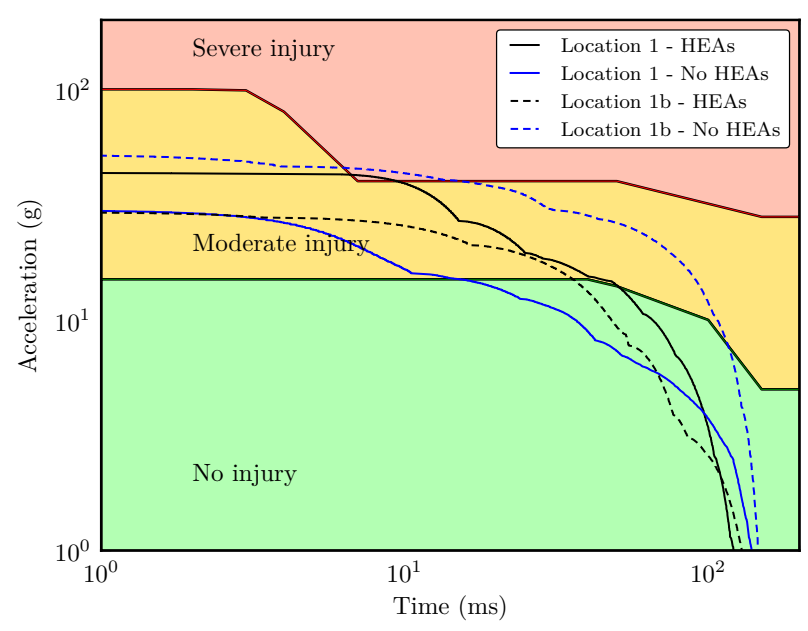

(b) Eiband diagram for locations $\mathbf{1}$ and $\mathbf{1 b}$.

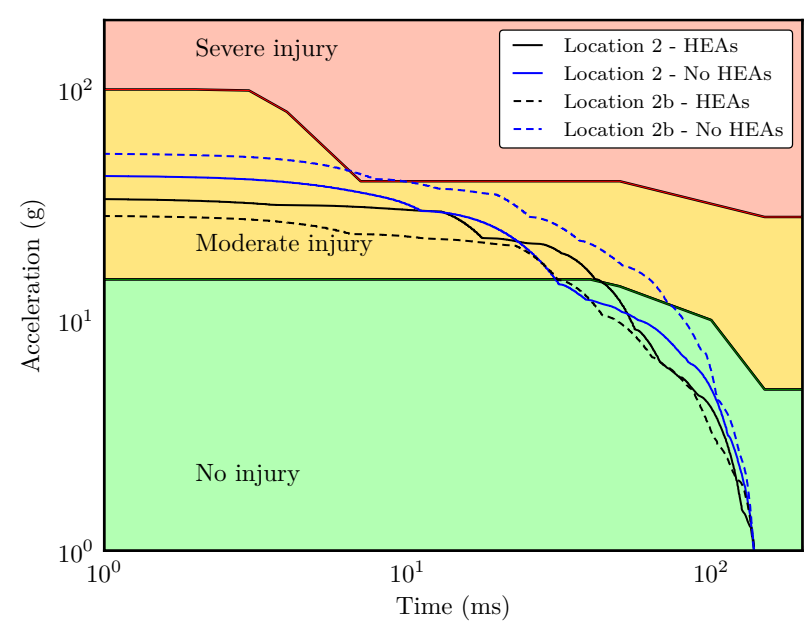

(d) Eiband diagram for locations $\mathbf{2}$ and $\mathbf{2 b}$.

Figure 22: Vertical accelerations and depiction in Eiband diagram. Fuselage with the auxiliary fuel tank, with and without energy absorbers. 


\begin{tabular}{lrrrr}
\hline & \multicolumn{2}{c}{ Original fuselage } & \multicolumn{2}{c}{ Enhanced fuselage } \\
\cline { 2 - 5 } Location & Max $(\mathrm{g})$ & $\operatorname{Avg}(\mathrm{g})$ & Max $(\mathrm{g})$ & Avg $(\mathrm{g})$ \\
\hline 1 & 29.94 & 7.14 & 43.44 & 17.01 \\
$\mathrm{~b}$ & 51.98 & 20.28 & 29.32 & 12.70 \\
\hline 2 & 42.32 & 10.84 & 33.62 & 13.14 \\
$2 \mathrm{~b}$ & 52.81 & 15.18 & 28.39 & 15.49 \\
\hline
\end{tabular}

Table 9: Acceleration maximums and averages for the fuselage with auxiliary fuel tank. Comparison between original and enhanced fuselage sections.

fuselage section from a Boeing 737-200 with and without the auxiliary fuel tank. The aircraft section was developed with the aid of technical drawings and later adjusted with the data in the literature from static and dynamic experiments in an iterative calibration process. Crashworthiness metrics are evaluated before and after the implementation of the energy absorbers to determine their overall effect on the aircraft. The following conclusions are drawn:

- For the fuselage numerical model validation, the qualitative comparison at different steps of the crushing process shows homologous collapse mechanisms between the experimental and verified numerical models. The vertical speed and acceleration trends at two locations in the fuselage station FS420 also deliver results with sensible agreement with experimental data, offering discordances smaller than $15 \%$ and $30 \%$ for magnitude and phase errors respectively .

- An Eiband diagram determine that injury ratings on the occupants, are more harmful in the scenario without the auxiliary fuel tank, as accelerations are well in the severe injury region with acceleration peaks of over 90 g's. The tank betters the overall behavior of the fuselage through progressive collapse and plastic dissipation than can reach up to $60 \mathrm{~kJ}$.

- Two different hybrid energy absorbers are designed and implemented in the fuselage without a fuel tank to improve the crashworthiness of the aircraft, with the square cross-section delivering better results than the circular variant. The position of the absorbers was also varied by increasing the transversal distance between struts by $16 \mathrm{~cm}$, although results worsen the original configuration.

- In the event of an impact without the auxiliary fuel tank, the usage of the square hybrid energy absorbers reduces the peak acceleration by up to $50 \%$ and provides 
a softer acceleration profile. The enhancement stems from the energy absorption provided by the struts as well as the plastic dissipation of the frames, increased from $76 \mathrm{~kJ}$ to $122 \mathrm{~kJ}$ as the absorbers modify the original structural collapse mechanism of the fuselage. Furthermore, the usage of crushable struts lowers the injury criteria from severe to moderate on both locations and ensures a bigger survivable space in the under-floor compartment.

- The addition of square crushable hybrid energy absorbers also enhances the crashworthiness performance of the aircraft. For the model with the fuel tank, peak acceleration is lowered up to $20 \mathrm{~g}$ at one of the measuring locations without significant detriment of the response at the others.

\section{Acknowledgements}

The research leading to these results has received funding from the Spanish Goverment (Ministerio de Economía, Industria, y Competitividad) under grant agreement DPI2016-76934-R, as well as funding from the Fundación Barrié. The authors fully acknowledge the support received.

\section{References}

[1] F. De Florio, Airworthiness: An Introduction to Aircraft Certification, Oxford, 2006.

[2] K. E. Jackson, R. L. Boitnott, E. L. Fasanella, L. E. Jones, K. H. Lyle, A history of full-scale aircraft and rotorcraft crash testing and simulation at nasa langley research center (2004).

[3] E. L. Fasanella, E. Widmayer, M. P. Robinson, Structural analysis of the controlled impact demonstration of a jet transport airplane., Journal of Aircraft 24 (1987) 274 280.

[4] M. Waimer, D. Kohlgrüber, D. Hachenberg, H. Voggenreiter, The kinematics model-a numerical method for the development of a crashworthy composite fuselage design of transport aircraft, in: Sixth triennial international aircraft fire and cabin safety research conference, 2010.

[5] A. Byar, T.-M. Tan, A crashworthiness study of a Boeing 737 fuselage section, Ph.D. thesis, Drexel University Philadelphia, PA, 2003. 
[6] S. Heimbs, Energy absorption in aircraft structures, International Workshop on Hydraulic Equipment and Support Systems for Mining (2012).

[7] M. McCarthy, C. Harte, J. Wiggenraad, A. Michielsen, D. Kohlgrueber, A. Kamoulakos, Finite element modelling of crash response of composite aerospace sub-floor structures, Computational Mechanics 26 (2000) 250-258.

[8] I. Kumakura, M. Minegishi, K. Iwasaki, Impact simulation of simplified structural models of aircraft fuselage, 2000 World Aviation Conference (2000).

[9] H. Shoji, M. Minegishi, T. Aoki, Impact characteristics estimation of channel section short column under axial impact load, Structural Dynamics and Materials Conference 4 (2007) 3967-3976.

[10] Y. Ren, J. Xiang, A comparative study of the crashworthiness of civil aircraft with different strut configurations, International Journal of Crashworthiness 15 (2010) $321-330$.

[11] X. Jia, G. Chen, Y. Yu, G. Li, J. Zhu, X. Luo, C. Duan, X. Yang, D. Hui, Effect of geometric factor, winding angle and pre-crack angle on quasi-static crushing behavior of filament wound cfrp cylinder, Composites Part B: Engineering 45 (2013) $1336-1343$.

[12] J. Paz, L. Romera, J. Diaz, Crashworthiness optimization of aircraft hybrid energy absorbers enclosing honeycomb and foam structures, AIAA Journal 55 (2017) 652661.

[13] Y. Ren, J. Xiang, The crashworthiness of civil aircraft using different quadrangular tubes as cabin-floor struts, International Journal of Crashworthiness 16 (2011) 253262.

[14] C. M. Kindervater, A. F. Johnson, D. Kohlgrüber, M. Lützenburger, N. Pentecote, Crash and impact simulation of aircraft structures-hybrid and fe based approaches, in: European congress on computational methods in applied sciences and engineering. Barcelona, Spain: ECCOMAS, 2000.

[15] E. L. Fasanella, K. E. Jackson, Crash simulation of vertical drop tests of two boeing 737 fuselage sections, in: U.S. Army Research Laboratory, Vehicle Technology Center, Langley Research Center, 2002. 
[16] A. Abromowitz, T. G. Smith, T. Vu, Vertical drop test of a narrow-body transport fuselage section with a conformable auxiliary fuel tank onboard, DOT/FAA/AR00/56 (2000).

[17] A. M. Eiband, Human tolerance to rapidly applied accelerations: a summary of the literature, National Aeronautics and Space Administration (NASA) (1959).

[18] B. C. Airplanes, 737 Airplane Characteristics for Airport Planning. D6-58325-6, 2013.

[19] G. R. Cook, W. H. Johson, A constitutive model and data for metals subjected to large strains, high strain rates and high temperatures, Proceedings of Seventh International Symposium on Ballistics (1983).

[20] G. Kay, Failure modeling of titanium 6AI-4V and aluminum 2024-T3 with the Johnson-Cook material model, Office of Aviation Research, Federal Aviation Administration, 2003.

[21] N. Brar, V. Joshi, B. Harris, Constitutive model constants for Al7075-T651 and Al7075-T6, in: Proceedings of the American Physical Society Topical Group on Shock Compression of Condensed Matter, volume 1195, AIP Publishing, 2009, pp. 945-948.

[22] E. L. Fasanella, K. E. Jackson, Best practices for crash modeling and simulation (2002).

[23] M. Costas, D. Morin, M. Langseth, L. Romera, J. Díaz, Axial crushing of aluminum extrusions filled with pet foam and gfrp. an experimental investigation, Thin-Walled Structures 99 (2016) 45-57.

[24] BASF, Ultramid (r) A3WG10 BK00564 Polyamide 66. Product information sheet, 2012.

[25] V. Deshpande, N. Fleck, Isotropic constitutive models for metallic foams, Journal of the Mechanics and Physics of Solids 48 (2000) 1253-1283.

[26] ABAQUS 6.16 Documentation, Dassault Systèmes, 2016.

[27] P. Schatrow, M. Waimer, Investigation of a crash concept for cfrp transport aircraft based on tension absorption, International journal of crashworthiness 19 (2014) $524-539$. 
[28] Boeing Commercial Airplanes, 737 Airplane Characteristics for Airport Planning, 2013.

[29] A. Adams, H. Lankarani, A modern aerospace modeling approach for evaluation of aircraft fuselage crashworthiness, International journal of crashworthiness 8 (2003) $401-413$.

[30] D. Y. Jeong, D. P. Roach, J. V. Canha, J. C. Brewer, T. H. Flournoy, Strain Fields in Boeing 737 Fuselage Lap Splices. Field and Laboratory Measurements with Analytical Correlations., Technical Report, DTIC Document, 1995.

[31] M. A. Sprague, T. L. Geers, Spectral elements and field separation for an acoustic fluid subject to cavitation, Journal of Computational Physics 184 (2003) 149-162.

[32] T. L. Geers, An objective error measure for the comparison of calculated and measured transient response histories, Shock and Vibration Information Center The Shock and Vibration Bull. 54, Pt. 2 p 99-108 (1984).

[33] B. Wang, G. Lu, Mushrooming of circular tubes under dynamic axial loading, Thinwalled structures 40 (2002) 167-182.

[34] S. Guillow, G. Lu, R. Grzebieta, Quasi-static axial compression of thin-walled circular aluminium tubes, International Journal of Mechanical Sciences 43 (2001) 2103-2123.

[35] S. Reid, Plastic deformation mechanisms in axially compressed metal tubes used as impact energy absorbers, International Journal of Mechanical Sciences 35 (1993) 1035-1052. 